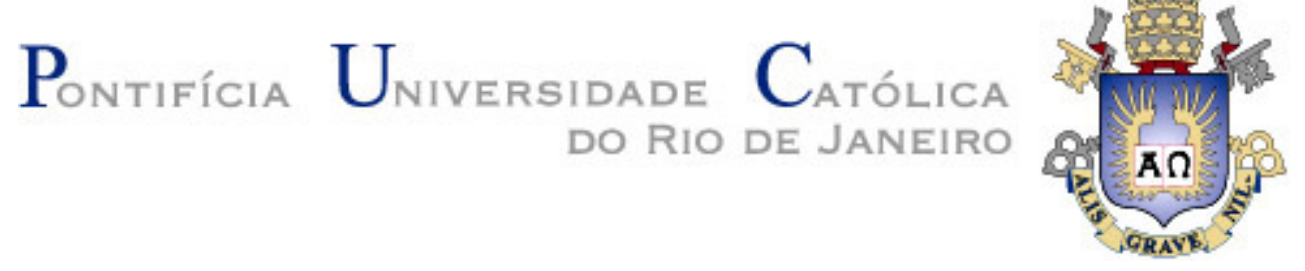

Renata Carvalho

\title{
A Relação entre a Cultura e o Desempenho Organizacional numa Instituição de Seguros
}

Dissertação de Mestrado

Dissertação apresentada ao Programa de Pósgraduação em Administração de Empresas da PUCRio como requisito parcial para obtenção do título de Mestre em Administração de Empresas

Orientadora: Profa. Patricia Amélia Tomei

Rio de Janeiro

Fevereiro de 2018. 
Renata Carvalho

\title{
A Relação entre a Cultura e o Desempenho Organizacional numa Instituição de Seguros
}

\begin{abstract}
Dissertação apresentada como requisito parcial para obtenção do grau de Mestre pelo Programa de Pós-Graduação em Administração de Empresas da PUC-Rio. Aprovada pela Comissão Examinadora abaixo assinada.
\end{abstract}

Prof-. Patricia Amélia Tomei

Orientadora

Departamento de Administração - PUC-Rio

Profa. Flávia de Souza Costa Neves Cavazotte

Departamento de Administração - PUC-Rio

Giuseppe Maria Russo

Dedix Assessoria Técnico-Científica

Prof. Augusto Cesar Pinheiro da Silva

Vice Decano de Pós-Graduação do CCS - PUC-Rio

Rio de Janeiro, 26 de fevereiro de 2018 
Todos os direitos reservados. É proibida a reprodução total ou parcial do trabalho sem autorização da universidade, da autora e da orientadora.

\section{Renata Carvalho}

Graduou-se em Psicologia pela Universidade Federal do Rio de Janeiro em 1997. Concluiu o MBA Executivo em Administração de empresas com ênfase em RH pela Fundação Getúlio Vargas no RJ em 2007. Atualmente é Gerente de Recursos Humanos em uma empresa do mercado segurador, sendo responsável pelos processos de treinamento e desenvolvimento, desempenho e clima organizacional.

Ficha Catalográfica

Carvalho, Renata

A relação entre a cultura e o desempenho organizacional numa instituição de seguros / Renata Carvalho ; orientadora: Patrícia Amélia Tomei. - 2018.

80 f. : il. color. ; $30 \mathrm{~cm}$

Dissertação (mestrado)-Pontifícia Universidade Católica do Rio de Janeiro, Departamento de Administração, 2018. Inclui bibliografia

1. Administração - Teses. 2. Cultura organizacional. 3. Modelo de cultura organizacional de Denison. 4. Desempenho. I. Tomei, Patrícia Amélia. II. Pontifícia Universidade Católica do Rio de Janeiro. Departamento de Administração. III. Título. 
Este trabalho é dedicado à minha mãe, incansável na arte de educar, ao amor da minha vida e ao meu filho, fontes de inspiração para tudo que faço! 


\section{Agradecimentos}

Ao meu esposo e ao meu filho, pela paciência, companheirismo e apoio durante a elaboração desta dissertação e ao longo do Mestrado.

Aos meus pais, minhas irmãs, sobrinho e "amigas-irmãs", por me apoiarem nas minhas escolhas e torcerem por mim em todos os momentos da minha vida.

A professora Patricia Tomei, pelo desafio constante, comentários, sugestões e confiança no processo de elaboração deste trabalho.

Aos professores e colegas do Mestrado, em especial aos que estiverem comigo nas disciplinas de Organizações, por todo aprendizado e compartilhamento de ideias que contribuíram para esta formação.

A alta liderança e aos gestores da Empresa X, pelo apoio e dedicação de tempo à pesquisa.

E a todos aqueles que me deram indicação de textos, autores, insights, apoio e incentivo ao longo da execução desta pesquisa. 


\section{Resumo}

Carvalho, Renata; Tomei, Patrícia Amélia. A Relação entre a Cultura e o Desempenho Organizacional numa Instituição de Seguros. Rio de Janeiro, 2018. 80p. Dissertação de Mestrado - Departamento de Administração, Pontifícia Universidade Católica do Rio de Janeiro.

Entender como características culturais interferem no desempenho de uma empresa, é extremamente relevante em mercados cada vez mais competitivos e dinâmicos. Assim sendo, o objetivo deste trabalho é analisar a relação da Cultura e o Desempenho Organizacional. A partir da revisão da literatura foi realizado um estudo de caso em uma empresa privada do setor de seguros, que se destaca no mercado em que atua, estando entre as maiores seguradoras independentes do Brasil em Vida, Previdência e Capitalização e ao longo dos anos, recebeu prêmios e participou dos mais importantes rankings financeiros nacionais, reunindo certificações que reforçam a credibilidade, o desempenho e a excelência em sua gestão. A pesquisa coletou dados referentes ao resultado do desempenho organizacional, mais especificamente o resultado dos indicadores financeiros Return on Sales (ROS), Return on Asset (ROA) e Retorno sobre Patrimônio Líquido (ROE) e, pela aplicação do questionário do modelo de Cultura Organizacional de Denison - DOCS (1990) no seu quadro gerencial, foi possível avaliar as características chaves da cultura organizacional, sob as dimensões de Missão, Consistência, Envolvimento e Adaptabilidade. A análise qualitativa dos dados coletados evidenciou que existe relação entre o resultado das dimensões culturais e os indicadores de rentabilidade, e sugere a importância do aprofundamento desta linha de pesquisa em outras organizações.

\section{Palavras-chave}

Cultura organizacional; modelo de Cultura Organizacional de Denison; desempenho 


\section{Abstract}

Carvalho, Renata; Tomei, Patrícia Amélia (Advisor). The Relationship between Culture and Organizational Performance in an Insurance Institution. Rio de Janeiro, 2018. 80p. Dissertação de Mestrado Departamento de Administração, Pontifícia Universidade Católica do Rio de Janeiro.

Understanding how organizational cultures interfere with a company's performance, and what are the important cultural characteristics to leverage this performance, is extremely relevant in increasingly competitive and dynamic markets. Therefore, the objective of this work is to analyze the relationship between Culture and Organizational Performance. From the literature review, a case study was conducted in a private insurance company, which stands out in the market in which it operates, being among the largest independent insurers in Brazil in Life, Private Pension and Savings Bonds and over the years, received awards and participated in the most important national financial rankings, gathering certifications that reinforce the credibility, the performance and the excellence in its management. The survey collected data on the results of organizational performance, more specifically the result of the financial indicators - Return on Sales (ROS), Return on Asset (ROA) and Return on Equity (ROE) and, by applying the Denison Organizational Culture Model - DOCS questionnaire to managers, it was possible to evaluate the key characteristics of the organizational culture, under the dimensions of Mission, Consistency, Involvement and Adaptability. The qualitative analysis of the data collected showed that there is a relationship between the results of the cultural dimensions and the indicators of profitability and suggests the importance of future research on this subject in other organizations.

\section{Keywords}

Organizational Culture; Denison Organizational Culture Model - DOCS; performance 


\section{Sumário}

1. O problema 12

1.1. Introdução 12

1.2. Objetivo final 14

1.3. Objetivos Intermediários 14

1.4. Delimitação do estudo 15

1.5. Relevância do estudo 15

2. Referencial teórico 18

2.1. Cultura Organizacional - Conceitos 18

2.2. Caracterização da Cultura Organizacional 21

2.3. Tipologias e Modelos culturais 22

2.3.1. O modelo de Denison (The Denison Organizational Culture
Model - DOCS)

2.3.1.1. Missão 25

2.3.1.2. Consistência 26

2.3.1.3. Envolvimento $\quad 27$

2.3.1.4. Adaptabilidade $\quad 27$

2.3.1.5. Foco externo (adaptabilidade mais missão) 28

2.3.1.6. Foco interno (envolvimento mais consistência) 28

2.3.1.7. Estabilidade (missão mais consistência) 29

2.3.1.8. Flexibilidade (adaptabilidade mais envolvimento) 29

2.3.1.9. Alinhamento ascendente e descendente (missão mais
envolvimento)

2.3.1.10. Cadeia de valor do cliente (adaptabilidade mais consistência) 29

2.3.2. Estudos e pesquisas $\quad 30$

2.4. Desempenho Organizacional 34

2.4.1. Desempenho Financeiro 35

2.4.1.1. Return on Sales (ROS) 36

2.4.1.2. Return on Assets (ROA) 36

2.4.1.3. Retorno sobre Patrimônio Líquido (ROE) 36

3. Metodologia 38

3.1. Tipo de pesquisa 38

3.2. Universo e amostra 39

3.3. Seleção dos sujeitos $\quad 40$

3.4. Procedimentos e Instrumentos de Coleta de Dados 40

3.5. Tratamento dos dados 41

3.6. Limitações do estudo (Limitações do método) 41

4. Descrição e Análise dos Resultados 43

4.1. A empresa 43

4.1.1. Sua história $\quad 44$

4.2. A Cultura Organizacional da EMPRESA X 46

4.2.1. Visão geral 46

4.2.2. Missão $\quad 47$

4.2.3. Consistência 49 
4.2.4. Envolvimento 51

4.2.5. Adaptabilidade 52

4.2.6. Foco externo 54

4.2.7. Foco interno $\quad 55$

4.2.8. Estabilidade 56

4.2.9. Flexibilidade $\quad 57$

4.2.10. Alinhamento ascendente e descendente 58

4.2.11. Cadeia de valor do cliente $\quad 59$

4.3. Apresentação e análise do Desempenho Financeiro 59

4.3.1. Ativo Total 60

4.3.2. Patrimônio líquido $\quad 61$

4.3.3. Lucro líquido 61

4.3.4. Faturamento 62

4.3.5. Return on Sales (ROS) 62

4.3.6. Return on Assets (ROA) 64

4.3.7. Retorno sobre Patrimônio Líquido (ROE) 64

5. Conclusão 66

5.1. Sugestões e recomendações para novas pesquisas 67

6. Referências Bibliográficas $\quad 69$

$\begin{array}{ll}\text { Anexo } 1 & 77\end{array}$ 


\section{Lista de figuras}

Figura 1: Organizational Culture Survey: Items by Index and Trait........25

Figura 2: Resultado geral da Pesquisa de Cultura .................................46

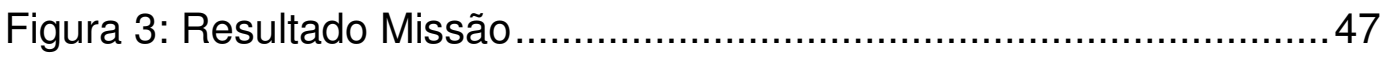

Figura 4: Resultado Consistência....................................................... 49

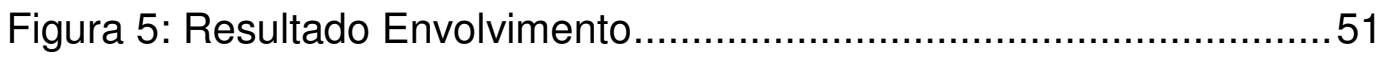

Figura 6: Resultado Adaptabilidade ................................................. 52

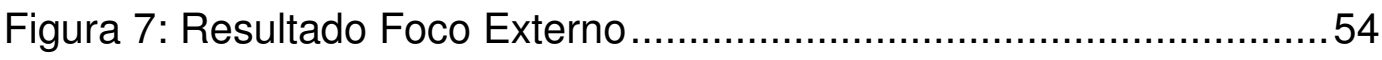

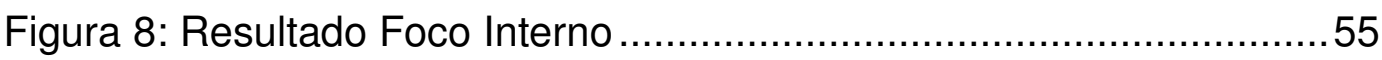

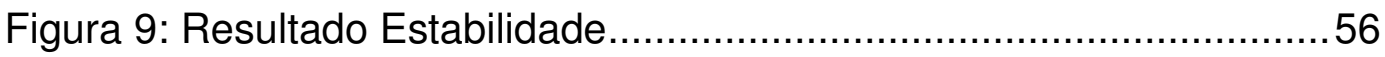

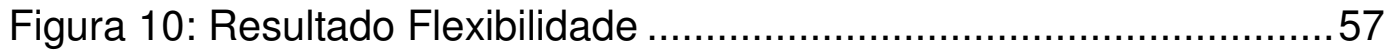

Figura 11 Resultado Alinhamento Ascendente e Descendente ...............58

Figura 12: Resultado Cadeia de Valor do Cliente ..................................59

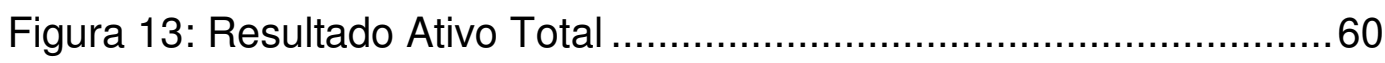

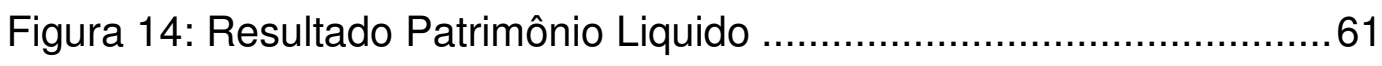

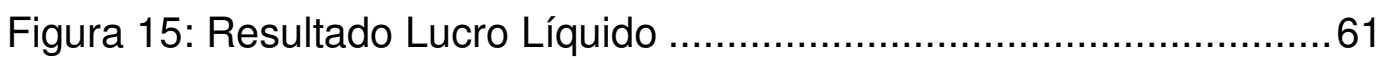

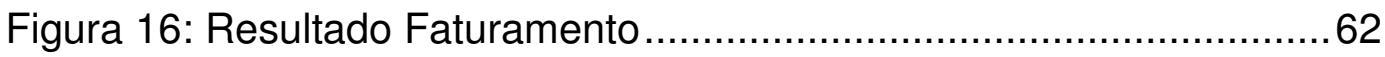

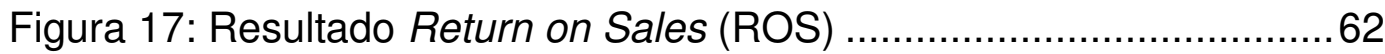

Figura 18: Resultado Cultura e Return on Sales (ROS) ..........................63

Figura 19: Resultado Return on Assets (ROA)........................................ 64

Figura 20: Resultado Retorno sobre Patrimonio Líquido..........................64

Figura 21: Resultado Cultura e Return on Investment ............................65 


\section{Lista de tabelas}

Tabela 1: Dados da amostra...................................................39 


\section{1 \\ O problema}

1.1.

Introdução

O conceito de cultura organizacional diz respeito às conclusões que um grupo de pessoas tem a partir de suas experiências dentro da organização. De forma mais objetiva, é a regra do jogo, a maneira como as coisas são feitas (PETTIGREW, 1979; SCHEIN, 1990).

Neste sentido, a cultura organizacional é importante porque proporciona consistência para uma organização e para as pessoas, ensina ordem e estrutura para as atividades internas da empresa, estabelece os padrões de relacionamento entre as pessoas (por meio de fronteiras, regras básicas e padrões para a comunicação), cria critérios para a entrada e a permanência dos membros na organização, além de determinar as condições para a efetividade dos processos internos, por meio de condições de premiações e punições (TOMEI, 2008).

Segundo Kotter e Heskett (1992), a ideia de que a cultura pode prejudicar ou ajudar o desempenho organizacional começou a ter destaque a partir dos anos 70, quando algumas universidades e consultorias (Harvard, Stanford, MIT, McKinsey e MAC) começaram a afirmar a importância do que foi chamado cultura corporativa ou organizacional baseado principalmente em pesquisas com empresas japonesas que consistentemente superaram suas concorrentes americanas.

Em todos os casos, independente das diferenças do foco, metodologia, terminologia usada, a conclusão fundamental era similar: as empresas tinham uma cultura corporativa que podia exercer um poderoso efeito nos indivíduos e seus desempenhos, principalmente em ambientes competitivos e esta influência podia até ser maior do que a de outros fatores como estratégia, estrutura organizacional, sistemas de gestão, ferramentas de analises financeiras, liderança, etc. 
Assim, diante da busca de respostas e novas ideias, livros publicados nos anos 80 como Theory $Z$ de Ouchi (1981), The Art of Japenese Management de Pascale e Atho (1981), Corporate Cultures de Deal e Kennedy (1982) e In Search of Excellence de Peters e Watermans (1982) tornaram-se best sellers e incentivaram novos estudos que introduziram a questão da relação entre cultura e desempenho.

Entre 1987 e 1991, Kotter e Heskett (1992), conduziram 4 estudos para determinar a relação entre cultura organizacional e o desempenho econômico de longo prazo, para clarificar a natureza desta relação e descobrir se e como esta relação podia ser explorada para aumentar o desempenho organizacional.

Estes estudos mostraram que:

- A cultura organizacional poderá ter um significativo impacto no desempenho econômico de longo prazo - após um período de 11 anos, empresas que enfatizavam clientes, acionistas, funcionários e lideres aumentaram as receitas em uma média de $682 \%$ frente a um aumento de $116 \%$; expandiram sua força de trabalho em $282 \%$ frente a $36 \%$, tiveram um crescimento de suas ações em $901 \%$ frente a $74 \%$ e aumentaram sua renda liquida em $756 \%$ frente a $1 \%$ das que não tinham este traço cultural;

- A cultura organizacional será, provavelmente, o fator mais importante na determinação do sucesso ou fracasso das organizações - em um mundo que está mudando a uma taxa crescente, se poderia prever que as culturas inadaptadas teriam um impacto financeiro negativo ainda maior;

- Não são raras as culturas organizacionais que inibem um forte desempenho financeiro de longo prazo - culturas que encorajariam comportamentos inadequados e inibiriam a mudança para uma melhor estratégia tenderiam a emergir lenta e silenciosamente por anos, usualmente quando estas organizações apresentam bom desempenho. E poderiam ser invisíveis para os envolvidos porque são suportadas pelo poder da estrutura existente, por várias razões;

- Apesar da resistência a mudança, a cultura organizacional pode ser aprimorada no desempenho, e para tanto, a liderança deve ser guiada por uma visão realista de que tipos de cultura impulsionam o desempenho. 
A cultura organizacional estabelece as condições para determinar a eficácia interna (SCHNEIDER, 1995). Determina se o desempenho é efetivo ou ineficaz e o que efetivo e ineficaz significam na organização (KWANTES e BOGLARSKY, 2007). Organizações cuja cultura fortalece a participação dos funcionários na tomada de decisão, estabelecem objetivos claros e lógicos e adaptam os métodos de trabalho para o trabalho ideal, tem melhor desempenho do que aquelas que apresentam menos desses fatores (HERIS, 2014).

Assim, conhecer a cultura organizacional é fundamental para a administração e implantação de estratégias que visem melhorar o desempenho de uma organização (FREITAS, 1991). Aplicar práticas de gerenciamento positivas, focadas nos funcionários e consistentes com os valores defendidos pela cultura do grupo, provavelmente irão inspirá-los a serem mais esforçados na realização do seu trabalho, o que deverá resultar em níveis mais elevados de eficácia organizacional (GREGORY et al., 2009).

Os textos acima demonstram que a cultura organizacional que possuiu determinados traços apresenta melhor desempenho.

Diante do exposto, a questão que se coloca é: qual a relação entre a cultura e desempenho organizacional, isto e, quais os traços da cultura que favorecem o desempenho organizacional?

\section{2. \\ Objetivo final}

O objetivo final deste trabalho é analisar a relação da Cultura e o Desempenho Organizacional.

\section{3.}

\section{Objetivos Intermediários}

E para atingir este objetivo final, os seguintes objetivos intermediários serão buscados:

$\checkmark$ Conceituar e delimitar cultura e desempenho organizacionais;

$\checkmark$ Apresentar o modelo de Cultura Organizacional de Denison (The Denison Organizational Culture Model - DOCS, 1990);

$\checkmark$ Apresentar a organização que será utilizada para alcançar o objetivo final;

$\checkmark$ Apresentar indicadores de desempenho escolhidos para a análise do desempenho desta empresa. 


\section{4. \\ Delimitação do estudo}

Vários fatores afetam o desempenho organizacional como por exemplo: a estratégia, a redução da rotatividade e do estresse (MICHAEL, 2009; CABLE; JUDGE, 1996), o clima organizacional (PRITCHARD E KARASICK ,1973), a eficácia organizacional (DISKIENE; GOSTAUTAS, 2013; LAUVER; KRISTOFBROWN, 2001; LOPEZ, 2009), o estilo de liderança e estrutura organizacional (CHELLADURAI E HAGGERTY, 1991), práticas de seleção rigorosas e socialização extensiva (SNELL E YOUNDT, 1995), o tamanho da organização, o setor de atividades, as barreiras de entrada da indústria, o comprometimento (ARTHUR,1994, AMOS; WEATHINGTON, 2008; CHATMAN, 1991; IPLIK et al., 2011), assim como a concorrência, aspectos regulatórios, marketing e estratégia.

Neste trabalho optou-se por focar a analise apenas na relação entre a cultura e o desempenho organizacional pincelando a relação entre manifestações culturais com indicadores de resultados empresariais.

Desta forma, este estudo está delimitado na investigação do relacionamento entre a cultura, questões relacionadas as suas práticas culturais e seu desempenho organizacional, mais especificamente no desempenho financeiro, apesar de termos ciência de que existem outras medidas de desempenho, como participação no mercado, satisfação de funcionários e qualidade dos produtos. Os relacionamentos de outros fatores com o desempenho corporativo e o grau em que estes fatores impactam a performance não serão abordados neste trabalho.

\section{5 .}

\section{Relevância do estudo}

Diversas investigações, abordagens, perspectivas e análises estão sendo elaboradas por pesquisadores e cientistas de inúmeras áreas do conhecimento, para estudar e interpretar a realidade das organizações.

Em recente artigo da Harvard Business Review, Groysberg et al. (2018) argumentam que estratégia e cultura estão entre as alavancas primárias à disposição dos líderes em sua busca na manutenção da viabilidade e eficácia organizacional. A estratégia oferece uma lógica formal para os objetivos da empresa e orienta as pessoas ao seu redor. Já a cultura expressa objetivos através de valores e crenças e guia a atividade através de suposições compartilhadas e normas de grupo. 
O conhecimento da cultura organizacional é fundamental para a administração e implementação de estratégias e mudanças que visem melhorar o desempenho de uma organização.

A cultura organizacional atua como um sistema de controle social e pode influenciar as atitudes e o comportamento (MACINTOSH E DOHERTY, 2010). E a relação entre cultura e comportamento é a base teórica para a afirmação de que a cultura influencia a eficácia (GREGORY et al., 2009).

Denison e Mishra (1995) mostraram que a cultura organizacional é um estimador forte para os índices de eficácia organizacional, entendida como a medida em que uma organização atinge seus objetivos (CAMERON, 1981; SCOTT, 1977).

Sharma e Good (2013) realizaram uma investigação empírica para identificar o impacto da cultura organizacional no desempenho e na produtividade organizacional. Os resultados do estudo mostraram que a cultura organizacional era um ingrediente essencial do desempenho organizacional e uma fonte de vantagem competitiva sustentável (CHILDRESS, 2013; KOHTAMAKI, THORGREN e WINCENT, 2016).

A cultura organizacional desempenha um papel essencial no sucesso das unidades de negócios e há muitas evidências sobre a correlação positiva entre o desempenho organizacional e a cultura organizacional (ASHKANASY et al., 2000; KINICKI e KREITNER, 2006).

Agir sem conhecer as forças culturais pode ter resultados imprevisíveis e indesejáveis, visto que a cultura organizacional interage com recursos humanos, estrutura organizacional e incluirá crenças, atitudes, pressupostos e expectativas comuns direcionando comportamentos na ausência de uma lei ou instruções claras, sendo um poderoso recurso de propósito de identidade comum e diretrizes flexíveis (AHMADY et al., 2016).

$E$ pela necessidade de ser eficiente dentro de mercados cada vez mais competitivos e dinâmicos, encontrar como as culturas organizacionais interferem no desempenho de uma empresa, e quais são as características culturais importantes para alavancar este desempenho, é extremamente relevante, principalmente, à medida que mais e mais empresas sofrem algum tipo de alteração em suas características culturais. 
Muitas pesquisas foram realizadas neste campo e mostraram que conhecer a cultura organizacional foi uma das prioridades dos gerentes. Seu efeito tem sido tão alto que, tendo conhecimento das dimensões culturais, é possível que se preveja e se direcione programas de curto e longo prazo e se prepare para atuar em um mercado competitivo e cheio de mudanças e aumente a sustentabilidade do negócio. O princípio da cultura organizacional poderia simplesmente facilitar as mudanças e estabilizar novas orientações em uma organização (MONAVARIAN e BAKHTAE, 2006).

Com base nesses argumentos, pode-se observar, que as constantes transformações do mundo globalizado interferem nas organizações, fazendo com que a área da cultura e da mudança organizacionais sejam um campo bastante vasto para a pesquisa científica.

A empresa pesquisada se destaca no mercado em que atua, estando entre as maiores seguradoras independentes do Brasil em Vida, Previdência e Capitalização e ao longo dos anos, recebeu prêmios e participou dos mais importantes rankings financeiros nacionais, reunindo certificações que reforçam a credibilidade, o desempenho e a excelência em sua gestão.

Conhecer a relação entre a cultura e o desempenho organizacional podem favorecer a tomada de decisão, planejamento e possível mudança organizacional e, dessa forma, desperta a atenção da autora e a motiva para aprofundar os seus conhecimentos teóricos e práticos. 


\section{2 \\ Referencial teórico}

Para atingir os objetivos final e intermediários deste estudo serão feitas uma revisão bibliográfica e a análise de trabalhos sobre o tema cultura organizacional, aspectos relacionados a cultura e o desempenho organizacional.

Nas seções um e dois, para localizar o leitor e fixar alguns parâmetros e premissas, será apresentado o conceito de cultura organizacional e como podemos caracterizar a cultura de uma organização.

Na seção três será apresentado um modelo de conexão entre cultura e desempenho que permitirá ao leitor o entendimento do impacto da cultura no desempenho sob diversas perspectivas.

E a seção quatro abordará os conceitos de desempenho organizacional e desempenho financeiro e trará uma breve explicação dos indicadores que serão utilizados neste estudo.

\section{1. \\ Cultura organizacional - conceitos}

As definições que cultura organizacional tem recebido tem diversos termos em comum, como costumes, valores, crenças e modo de agir, entre outras, que aparecem em grande parte das definições existentes.

Reichers e Schneider (1990) identificam o início da evolução da construção da cultura com um artigo de Pettigrew (1979) que introduziu o conceito antropológico de cultura para a comunidade científica e mostrou como o conceito poderia ser usado na análise organizacional. Pettigrew (1979, p. 574), o descreve como "o sistema de significados aceitos publicamente e coletivamente, operando para um determinado grupo em um determinado momento".

Este conceito influencia Dandridge, Mitroff e Joyce (1980), que introduzem o termo simbolismo organizacional, com o qual eles referem que uma análise dos símbolos e seus respectivos usos trarão uma compreensão completa de todos os aspectos de um sistema. Portanto, a cultura organizacional será melhor estudada a partir da profunda revelação dos aspectos de uma organização. 
Schwartz e Davis (1981, p. 33) afirmam que a cultura organizacional é "um padrão das crenças e expectativas compartilhadas pelos membros da organização. Essas crenças e expectativas produzem normas que moldam poderosamente o comportamento de indivíduos e grupos na organização". Conceito expandido, anos depois, por Barney (1986), que acrescentou que é possível transformá-la em vantagem competitiva.

Ainda segundo Vertel (2013), Martin e Siehl (1983) explicam que a cultura de uma organização pode sofrer mudanças espontâneas, intencionalmente pela administração, ou por subculturas que possam ajudar a reforçar a cultura principal. Wilkins (1983) descreve que a cultura é o comportamento habitual das pessoas e a maneira pela qual eles veem o mundo (histórias, línguas e costumes) e, portanto, de várias análises. Kilmann, Saxton e Serpa (1985, p. 5) enfatizam que a "cultura pode ser definida como as filosofias, ideologias, valores, pressupostos, crenças, expectativas, atitudes e normas compartilhadas, que mantêm a comunidade unida".

Smircich (1983) identifica duas linhas distintas para a definição de cultura organizacional: a primeira, tratando-a como uma variável independente, resposta à sociedade à qual pertence, sendo absorvida e inserida na organização por meio dos membros dessa sociedade, e sendo, dessa forma, externa à organização. E a segunda, como uma variável interna, na qual as organizações são, elas mesmas, responsáveis pelo fenômeno da formação de determinada cultura, produzindo produtos culturais, como lendas e cerimônias.

Lorsch (1985) usa o termo cultura como as crenças compartilhadas entre gerentes e outros empregados, frequentemente invisíveis, até para as próprias pessoas da organização, apesar de exercerem grande impacto sobre seus pensamentos e ações.

Cooke e Rousseau (1988, p. 255) nos dizem que a cultura "reflete maneiras de pensar e acreditar que os membros têm em comum". Rousseau continua seu trabalho e, em 1990, define a cultura como um fenômeno de nível unitário derivado da interação social. A cultura deriva das crenças normativas, "o que deve ser feito", e as normas são caracterizadas por Cooke e Rousseau (1988, p. 255) como "expectativas comparadas relevantes para todos os membros."

Segundo Deshpande e Webster (1989, p. 4), a cultura organizacional pode ser compreendida como "um padrão compartilhado de crenças e valores que ajudam os indivíduos a entender o funcionamento organizacional e também provê a eles normas para o comportamento na organização". 
A cultura como algo que uma organização possui é definida por Schein (1990, p. 111) como: "(a) um padrão de hipóteses básicas, (b) inventado, descoberto ou desenvolvido por um determinado grupo, (c) como ele aprende a lidar com seus problemas de adaptação externa e integração interna, (d) que funcionou bem o suficiente para ser considerado válido e, portanto, (e) deve ser ensinado a novos membros como (f) a maneira correta de perceber, pensar e sentir em relação a esses problemas." Schein (1990) sugere que várias culturas são possíveis em uma organização. Reichers e Schneider (1990) resumem a definição de Schein (1990) como respostas aprendidas aos problemas de sobrevivência e integração interna do grupo. As respostas são subconscientes, consideradas aceitas e compartilhadas pelos membros do grupo.

O'Reilly, Chatman e Caldwell (1991) e Chatman e Jehn (1994) definem a cultura organizacional como um conjunto de valores compartilhados entre os membros da organização.

Denison (1996) suporta ideias anteriores e salienta que a cultura se refere à estrutura profunda das organizações, que está enraizada nos valores, crenças e premissas dos membros organizacionais. O significado é estabelecido através da socialização para uma variedade de grupos de identidade que convergem no local de trabalho. A interação reproduz um mundo simbólico que dá à cultura uma grande estabilidade e uma certa natureza precária e frágil enraizada na dependência do sistema na cognição e ação individual.

A cultura organizacional é um elemento importante para aumentar a competitividade e a produtividade da empresa, pois reconhece as capacidades intelectuais, o trabalho e a troca de ideias entre os grupos, facilitando a realização das atividades da empresa, criando um clima de companheirismo e, ao mesmo tempo, entregando um trabalho favorável ao seu nível de produção (SORIA, 2008).

A cultura organizacional inclui as normas que os membros de uma organização experimentam e descrevem como suas configurações de trabalho (SCHNEIDER et al., 2013). Essas normas determinam a forma como os membros se comportam e se adaptam para obter resultados na organização. A cultura organizacional é como os membros de uma organização interagem uns com os outros e outras partes interessadas (SIMONEAUX e STROUD, 2014). 
A cultura organizacional é um conjunto de valores, crenças e padrões de comportamento que diferenciam uma organização de outras organizações (ORTEGA-PARRA e SASTRE-CASTILLO, 2013). King (2012) definiu a cultura organizacional como um sistema de valores que, subconscientemente e silenciosamente, leva as pessoas a fazer cada escolha e decisão na organização.

Yirdaw (2014) observou que a cultura organizacional é a cola que combina o hardware (recursos não humanos) com o software (recursos humanos) na organização para estabelecer o trabalho em equipe e excelente desempenho.

Para este estudo, será usada a definição proposta por Schein (1990, p. 111), apresentada anteriormente.

\section{2.}

\section{Caracterização da cultura organizacional}

Esta seção irá elencar as características essenciais para a compreensão da cultura de uma organização.

Segundo Crozatti (1998), as principais características da cultura podem ser percebidas através dos seguintes conceitos:

- Crenças: verdades aceitas através da observação de fatos e pela convivência em um grupo de pessoas;

- Valores: elementos que determinam a importância das coisas. Representam uma predeterminação consciente da ação das pessoas;

- Costumes: materialização dos valores e crenças através dos atos realizados de forma um tanto quanto sistemática;

- Ritos: operações rotineiras executadas para êxito das atividades;

- Cerimônias: encontros formais e informais de um grupo social. Funcionam como meios de reafirmar ou ratificar valores, crenças e costumes;

- Rede de comunicação informal: funciona como meio de atualização de crenças, valores e mitos. Através desta rede, a cultura da empresa é reciclada e reafirmada. 
Schein (2004) considera que a cultura organizacional pode ser aprendida a partir de diferentes níveis, que estão relacionados ao grau pelo qual o fenômeno cultural é visível ao observador. Segundo o autor, é necessário diferenciar os níveis em que a cultura se manifesta para efetivamente compreender sua definição:

a) Nível dos artefatos visíveis - equivalente ao ambiente construído da organização, a arquitetura do ambiente físico, as rotinas e os processos de trabalho, layout da organização, tecnologia empregada e produtos, a maneira de as pessoas se vestirem, a maneira de comunicar, documentos, modelos de comportamentos visíveis e audíveis, mitos e histórias contados sobre a organização.

b) Nível dos valores - os valores concedem maior possibilidade de aprender a cultura do que no nível dos artefatos visíveis, porém, uma vez identificados, geralmente representam apenas o conteúdo manifesto da cultura por expressarem o que as pessoas reportam ser a razão do seu comportamento, o que na maioria das vezes, são idealizações ou racionalizações;

c) Nível dos pressupostos básicos subjacentes - suposições implícitas que orientam o comportamento dos membros do grupo determinando como perceber, refletir e sentir as coisas. São formados na organização, na medida em que certos valores, anteriormente conscientes, são compartilhados pelo grupo, conduzindo-os a determinados comportamentos. Uma vez que esses comportamentos se mostram adequados para solucionar problemas, o valor é gradualmente transformado em pressuposto inconsciente, sobre como as coisas realmente são e, internalizado como verdade, passando a ser inquestionável.

Schein (2004) argumenta que qualquer cultura organizacional pode ser estudada nesses três níveis, ressaltando que a essência de uma cultura está nos pressupostos básicos e seu entendimento facilita a compreensão dos outros níveis.

\section{3.}

\section{Tipologias e modelos culturais}

Este estudo apoia uma relação entre o tipo de cultura organizacional e o desempenho da organização. Em uma abordagem de tipo (ou traço, ou conteúdo), assume-se que um determinado valor ou crença tem um efeito particular na organização. 
Segundo Tomei (2011, p. 113), as "tipologias culturais são modelos que ajudam na compreensão da cultura organizacional, pois remetem a generalizações de um objeto".

Apesar de reconhecermos que existem várias tipologias e modelos que ajudam nesta compreensão, como aqueles desenvolvidos por Handy (1976), Sethia e Glinow (1985), Deal e Kennedy (1982), Quinn e Rohrbaugh (1983), Rob Goffee e Jones (2001) e Barros e Prates (1996), o presente estudo será fundamentado no modelo desenvolvido por Denison e seus colegas (DENISON, 1984, 1990, 1996; DENISON e MISHRA, 1995; DENISON e NEALE, 1996; DENISON, CHO e YOUNG, 2000; DENISON, HAALAND e NEALE, 2002).

Segundo Mario Ernesto (2010), este modelo tem, por um lado, o coração colocado sobre os pressupostos e as crenças que mantêm a coesão organizacional e, por outro lado, um interesse central na influência da cultura organizacional sobre o desempenho (DENISON e MISHRA, 1995; DENISON e NEALE, 1996; DENISON, 2000; FEY e DENISON, 2003). Acrescenta ainda que, estruturalmente, ele apresenta uma grande semelhança com o trabalho pioneiro sobre características da cultura, proposto por Harrison (1972); o trabalho de Cunha e Cooper (2002), e o modelo de Cameron e Quinn (1999) e do ponto de vista conceitual, baseia-se em grande parte nas obras de Schein (1985 e 1990).

Esta seção se propõe a detalhar o modelo e apresentar os resultados encontrados em artigos e dissertações com a sua aplicação.

\subsection{1.}

\section{O modelo de Denison (The Denison Organizational Culture Model - DOCS, 1990)}

O modelo apresentado por Denison (The Denison Organizational Culture Model - DOCS, 1990) e utilizado neste estudo, tem em seu cerne, as crenças e premissas subjacentes que representam os níveis mais profundos da cultura organizacional. São feitas comparações de organizações baseadas em valores e suas práticas manifestas. Esses valores são considerados mais acessíveis do que os pressupostos e mais confiáveis que os artefatos (YILMAZ e ERGUN, 2008).

Embora seja difícil medir estes níveis mais profundos da cultura organizacional, eles fornecem a base a partir da qual nascem o comportamento e a ação. As crenças e os pressupostos básicos sobre a organização e suas equipes, o cliente, o mercado, a indústria e a proposição de valor básico da empresa criam uma lógica coesa que mantem a organização unida (DENISON et al., 2013). 
Denison (1990) sustenta que a vinculação das práticas de gestão com os pressupostos e crenças subjacentes da organização é importante para o estudo da relação entre cultura e desempenho e fornece um quadro para conduzir a investigação. Com Mishra (1995), desenvolve The Denison Organizational Culture Model - DOCS, um modelo de cultura organizacional e eficácia baseada em quatro traços das culturas organizacionais: envolvimento, consistência, adaptabilidade e missão. Esses traços são examinados através de dois estudos vinculados: no primeiro, estudos de caso qualitativos de cinco empresas são usados para identificar os traços e a natureza de sua vinculação com a efetividade; e no segundo, um estudo quantitativo fornece uma análise exploratória das percepções dos CEOs desses quatro traços e sua relação com medidas subjetivas e objetivas de eficácia em uma amostra de 764 organizações.

Os resultados mostram suporte para o valor preditivo dos traços e ajudam a ilustrar a complementaridade de métodos qualitativos e quantitativos para estudar culturas organizacionais. Dois dos traços, envolvimento e adaptabilidade, são indicadores de flexibilidade, abertura e capacidade de resposta, e foram fortes preditores de crescimento. Os outros dois traços, consistência e missão, são indicadores de integração, direção e visão, e foram melhores preditores de rentabilidade. Cada um dos quatro traços também foram preditores significativos de outros critérios de eficácia, tais como qualidade, satisfação dos funcionários e desempenho geral. Os resultados também mostraram que os quatro traços eram fortes preditores de critérios de eficácia avaliados subjetivamente para a amostra total de empresas, mas eram fortes preditores de critérios objetivos, como retorno sobre ativos e crescimento de vendas apenas para empresas maiores.

Estes quatro traços da cultura organizacional foram expandidos por Denison e Neale (1996) e Denison, Janovics, Cho e Young (2006) para incluir três subdimensões para cada uma, passando para um total de 12 dimensões.

No modelo utilizado, apresentado na figura 1, usamos o Organizational Culture Survey: Items by Index and Trait (DENISON et al., 2006), que foi complementado por pontos apresentados no livro "A força da cultura organizacional nas empresas globais: como conduzir mudanças de impacto e alinhar estratégia e cultura." (DENISON et al., 2013).

Este modelo, além de dissertações e artigos do autor e de pesquisadores que utilizaram o mesmo modelo, serviu de parâmetros para a análise dos nossos resultados. 


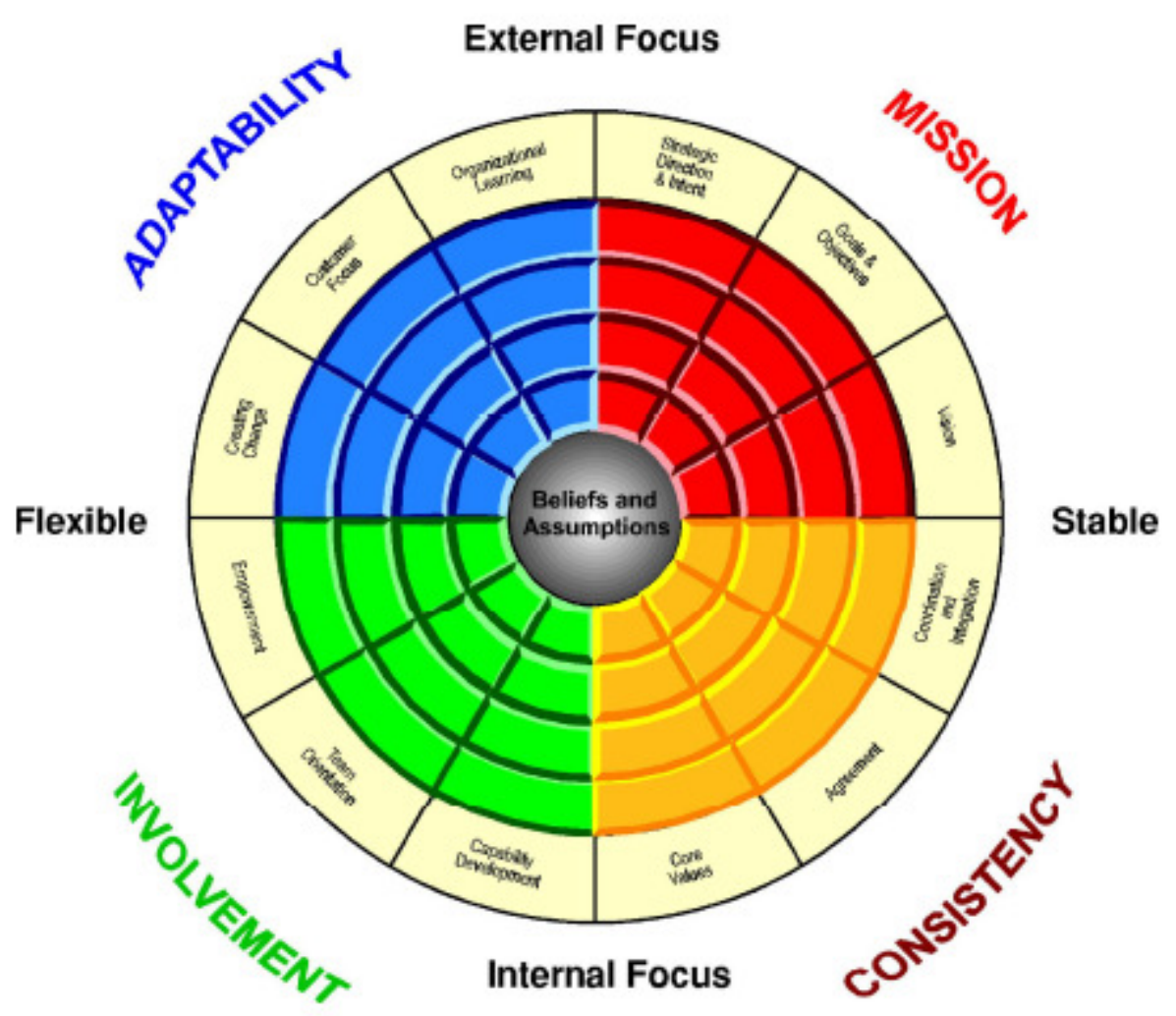

Figura 1 - Organizational Culture Survey: Items by Index and Trait

\subsubsection{1.}

Missão

Refere-se ao senso claro de propósito ou direção que define objetivos estratégicos e organizacionais. Está expresso na visão de futuro da organização. Os líderes desempenham papel critico na definição desta missão, mas ela só pode ser alcançada se for bem compreendida em todos os níveis organizacionais (de cima a baixo). Organizações bem-sucedidas têm um senso claro de propósito e direção que lhes permite definir metas organizacionais e objetivos estratégicos, e criar uma visão convincente do seu futuro (HAMEL e PRAHALAD, 1994; MINTZBERG, 1987, 1994; OHMAE, 1982).

Se subdivide em orientação estratégica e intenção, metas e objetivos e visão, sendo:

Orientação estratégica e intenção - As intenções estratégicas claras transmitem o propósito da organização e deixam claro como todos podem contribuir e "marcar a marca" na indústria. 
Metas e objetivos - Um conjunto claro de metas e objetivos pode ser vinculado à missão, visão e estratégia, e fornecer a todos uma direção clara em seu trabalho.

$\checkmark$ Visão - A organização possui uma visão compartilhada de um estado futuro desejado. Incorpora valores fundamentais e captura os corações e as mentes das pessoas da organização, ao mesmo tempo que fornece orientação e direção.

\subsubsection{2.}

\section{Consistência}

O comportamento está enraizado em um conjunto de valores fundamentais, e líderes e seguidores são habilidosos em colocar estes valores em pratica por um acordo abrangente, incorporando diversos pontos de vista (BLOCK, 1991). A consistência é uma poderosa fonte de estabilidade e integração interna que resulta de um quadro mental comum e de um alto grau de conformidade (SENGE, 1990). Essas organizações têm empregados altamente comprometidos, um método diferente de fazer negócios, tendência a promover pessoas e um conjunto claro do que fazer e não fazer (DENISON et al., 2013). Também tendem a ser eficazes porque têm culturas "fortes" altamente consistentes, bem coordenadas e bem integradas (DAVENPORT, 1993; SAFFOLD, 1988).

Se subdivide em valores fundamentais, acordo e coordenação e integração, sendo:

$\checkmark$ Valores fundamentais - Os membros da organização compartilham um conjunto de valores que criam um senso de identidade e um conjunto claro de expectativas.

$\checkmark$ Acordo - A organização pode chegar a um acordo sobre questões críticas. Isso inclui o nível de concordância subjacente e a capacidade de conciliar, quando ocorrem, as diferenças.

$\checkmark$ Coordenação e Integração - Diferentes funções e unidades da organização são capazes de trabalhar bem em conjunto para alcançar metas comuns. Os limites organizacionais não interferem com o trabalho feito. 


\subsubsection{3. \\ Envolvimento}

Definido como o empoderamento das pessoas, a construção pessoal em torno das equipes e o desenvolvimento da capacidade humana em todas as áreas da organização. Considera o compromisso dos diferentes trabalhadores e sua capacidade de influenciar em todas as áreas. Executivos, gerentes e funcionários são altamente comprometidos com seu trabalho e tem forte senso de compromisso e posse. Sentem que contribuem para as decisões que afetarão seu trabalho e que seu trabalho está conectado diretamente aos objetivos da organização (SPREITZER, 1995). Organizações eficazes capacitam e engajam suas equipes, constroem sua organização em torno de equipes e desenvolvem a capacidade humana em todos os níveis (BECKER, 1964; LAWLER, 1996; LIKERT, 1961).

Se subdivide em empoderamento, orientação da equipe e desenvolvimento de capacidades, sendo:

$\checkmark$ Empoderamento - Os indivíduos têm autoridade, iniciativa e habilidade para gerenciar seu próprio trabalho, criando um senso de propriedade e responsabilidade para com a organização.

$\checkmark$ Orientação da equipe - O valor está em trabalhar cooperativamente em direção a objetivos comuns para os quais todos os funcionários se sentem mutuamente responsáveis. A organização depende do esforço da equipe para fazer o trabalho.

$\checkmark$ Desenvolvimento de capacidade - A organização investe continuamente no desenvolvimento das habilidades dos funcionários para se manter competitiva e atender às necessidades do negócio.

\subsubsection{4.}

\section{Adaptabilidade}

Trata do grau de flexibilidade e capacidade de resposta ao ambiente de negócios, complementar ao senso de propósito e direção. A integração interna e a adaptação externa podem muitas vezes estar em desacordo. Organizações adaptáveis são conduzidas por seus clientes, assumem riscos e aprendem com seus erros, e possuem capacidade e experiência na criação de mudanças (NADLER, 1998; SENGE, 1990). Estão mudando continuamente o sistema para que melhorem as habilidades coletivas e forneçam valor para seus clientes (STALK, 1988). 
Se subdivide em criação da mudança, foco no cliente e aprendizagem organizacional, sendo:

$\checkmark$ Criação de mudanças - A organização é capaz de criar formas adaptativas para atender às necessidades de mudanças. É capaz de ler o ambiente de negócios, reagir rapidamente às tendências atuais $e$ antecipar as mudanças futuras.

$\checkmark$ Foco no cliente - A organização entende e reage a seus clientes e antecipa suas necessidades futuras. Esta subdimensão reflete o grau em que a organização é conduzida por uma preocupação para satisfazer seus clientes.

$\checkmark$ Aprendizagem organizacional - A organização recebe, traduz e interpreta os sinais do meio ambiente em oportunidades para incentivar a inovação, ganhar conhecimento e desenvolver capacidades.

Além dos traços culturais ou dimensões, este modelo estuda qualquer organização em termos de quatro tensões dinâmicas.

\subsubsection{5.}

\section{Foco externo (adaptabilidade mais missão)}

Uma organização com foco externo forte concentra-se na adaptação e mudança em resposta ao ambiente externo. Um foco externo forte geralmente influencia as receitas ou renda, o crescimento das vendas e a participação no mercado.

\subsubsection{6.}

\section{Foco interno (envolvimento mais consistência)}

Uma organização com um foco interno forte é normalmente concentrada na dinâmica da integração interna de sistemas, estruturas e processos. $O$ resultado destas dimensões afeta a qualidade, a satisfação dos funcionários e o retorno do investimento. Um foco interno forte está associado a qualidade de produtos e serviços, ou seja, os níveis mais altos de qualidade, menos defeitos e menos retrabalho, boa utilização dos recursos e alta satisfação dos funcionários. 


\subsubsection{7.}

\section{Estabilidade (missão mais consistência)}

Uma organização estável tem a capacidade de se manter focada e previsível ao longo do tempo. Está associada a medidas de desempenho financeiro como retorno sobre ativos, retorno de investimentos e retorno de vendas, bem como operações comerciais fortes.

\subsubsection{8.}

\section{Flexibilidade (adaptabilidade mais envolvimento)}

Uma organização flexível tem a capacidade de fazer mudanças em resposta ao meio ambiente. Seu objetivo é o mercado e suas pessoas. Uma empresa flexível geralmente está ligada a desenvolvimento de produtos e inovação, ou seja, níveis mais altos de inovação de produtos e serviços, criatividade e uma resposta rápida aos requisitos em mudança de clientes e funcionários.

O modelo ainda acrescenta duas outras tensões a serem gerenciadas.

\subsubsection{9.}

\section{Alinhamento ascendente e descendente (missão mais envolvimento)}

As organizações devem ter um equilíbrio entre a missão (de cima para baixo) e o envolvimento dos funcionários (de baixo para cima), vinculando o propósito e as estratégias da organização com o senso compartilhado de responsabilidade, propriedade e comprometimento dos funcionários. Quando há equilíbrio entre esses traços, vemos uma comunicação bidirecional eficaz e uma força de trabalho focada e comprometida.

\subsubsection{0.}

\section{Cadeia de valor do cliente (adaptabilidade mais consistência)}

Representada pela tensão criada entre adaptabilidade, que se preocupa amplamente com o mercado e a consistência, que analisa os valores, sistemas e processos internos. As organizações de alto desempenho devem ser capazes de se adaptar e responder ao mercado e desenvolver sistemas e processos que Ihes permitam executar de forma a produzir produtos e serviços de qualidade. 


\subsection{2. \\ Estudos e pesquisas}

Nesta seção vamos falar de pesquisas e estudos organizacionais que constam na literatura que analisaram a relação entre o desempenho e a cultura organizacional, e em especial aquelas que utilizaram o modelo de Denison (The Denison Organizational Culture Model - DOCS, 1990).

A literatura tem trazido informações sobre como os gestores do negócio tanto usam a cultura organizacional eficaz para melhorar o desempenho e a produtividade (FLAMHOLTZ E RANDLE, 2012; O'REILLY et al., 2014) como para (a) moldar as atitudes dos funcionários, (b) melhorar a eficácia operacional, e (c) aumentar o desempenho financeiro na organização (HARTNELL et al., 2011).

Outros resultados também demonstraram a associação entre cultura e desempenho geral, financeiro e resultados de vendas (DENISON, 1990; DENISON, HAALAND e GOELZER, 2003; FEY e DENISON, 2003).

Hause (2000) realizou uma pesquisa em 25 usinas geradoras de energia elétrica gerenciadas por uma única holding, onde examinou os méritos comparativos de nível (média das pontuações) e acordo (quantidade de consenso entre as respostas) como medidas de força de cultura organizacional na previsão de eficácia organizacional. Os resultados mostraram que tanto o nível, quanto as medidas de acordo da força da cultura organizacional, são preditivas da eficácia organizacional. Um problema de sensibilidade impediu o estabelecimento do nível (média das pontuações) como único preditor. No entanto, funcionou bem em combinação com o índice organizacional de preditores de acordo (consenso entre as respostas). Não foram descobertos efeitos conjuntos para as duas classes de preditores.

Yilmaz e Ergun (2008) examinaram os efeitos de quatro grandes traços da cultura organizacional (missão, consistência, envolvimento e adaptabilidade) sobre as medidas de desempenho, usando dados coletados de 143 empresas industriais na Turquia. A hipótese é de que cada traço cultural exerceria efeitos positivos sobre o desempenho da empresa e em uma grande variedade de medidas de eficácia (YILMAZ; ERGUN, 2008). A cultura corporativa foi medida por meio dos indicadores do The Denison Organizational Culture Survey (DOCS) (DENISON, 1990) e as medidas de desempenho utilizadas foram o crescimento das vendas, retorno sobre ativos, crescimento da participação de mercado, dentre outras métricas. Os resultados indicaram que o traço missão era o mais 
importante dos quatro traços em termos de promover o desempenho global da empresa, assim como o crescimento das vendas, o crescimento da participação de mercado e o retorno sobre ativos. Além disso, a capacidade de uma empresa para desenvolver novos produtos de sucesso foi influenciada principalmente pelas características de adaptabilidade e de consistência. A satisfação dos colaboradores foi determinada, em grande parte, pela característica envolvimento.

LaCasse (2010) conduziu um estudo com 749 funcionários de uma instituição correcional estadual e surpreendentemente, identificou que a maior pontuação estava na dimensão missão e não na dimensão consistência. Em uma cultura hierárquica, como uma instituição correcional, a eficiência interna, a uniformidade, a coordenação e a avaliação seriam enfatizadas (DENISON E SPREITZER, 1991). O foco estaria na lógica da organização interna e a ênfase, na estabilidade. $O$ objetivo das organizações com ênfase na cultura hierárquica tenderia a estar na execução de regulamentos e os fatores motivadores incluiriam segurança, ordem, regras e regulamentos. Os líderes tenderiam a ser conservadores e cautelosos, prestando muita atenção às questões técnicas. Os critérios de eficácia incluiriam controle, estabilidade e eficiência. Portanto, antecipava-se que a instituição correcional, demonstraria médias mais elevadas no quadrante de consistência. No entanto, a média mais elevada nas dimensões da instituição correcional estadual estava no quadrante da missão com uma média de 4,29. Além disso, os traços de consistência e envolvimento ficaram com médias 4.27 e 4.24, respectivamente, e o traço de adaptabilidade com uma média de 3.67.

Mario Ernesto (2010) realizou uma pesquisa sobre a cultura organizacional em uma amostra de empresas colombianas a partir de dois exercícios: (1) identificando elementos mínimos que deveriam ser considerados para examinar a pertinência de um modelo sobre a cultura organizacional e (2) um estudo exploratório sobre as relações entre cultura e desempenho organizacional com base no modelo de Denison (The Denison Organizational Culture Model DOCS, DENISON, 1990). Assim, depois de caracterizar o modelo no contexto dos estudos sobre cultura, buscou uma estrutura fatorial dos traços da cultura propostos no modelo (consistência, envolvimento, adaptabilidade e missão) e avaliou hipóteses que relacionavam traços da cultura com indicadores de desempenho organizacional. $O$ autor concluiu que a estrutura fatorial não se ajusta à estrutura esperada, e que somente o traço missão evidencia relações significativas com algumas medidas de desempenho. 
Kotrba et al. (2012) analisaram a ideia de que os efeitos da consistência cultural no desempenho corporativo podem variar de acordo com os níveis de outros traços culturais. Os autores utilizaram uma amostra de 137 empresas no período compreendido entre 1995 e 2005, com um número médio de 660 funcionários por empresa pesquisados no período. A cultura corporativa foi medida, assim como no estudo de Yilmaz e Ergun (2008), através dos indicadores de The Denison Organizational Culture Survey (DOCS) (DENISON, 1990), por meio de quatro traços da cultura (envolvimento, consistência, adaptabilidade e missão), cada um dos quais composto de três índices, para um total de 12 índices. Cada índice foi composto por cinco itens, de modo que cada traço contém 15 itens. As medidas de desempenho utilizadas foram: índice market-to-book, crescimento das vendas e retorno sobre os ativos. Os resultados mostraram que empresas que são ao mesmo tempo consistentes e adaptáveis, por exemplo, apresentam alto desempenho. Em contrapartida, os resultados mostram uma interação negativa significante na predição retorno sobre os ativos.

Turáková e Rečičár (2013) realizaram a análise da cultura corporativa em três empresas da indústria química localizadas no leste da Eslováquia. Este estudo contou com a presença de 558 entrevistados, representando $71,3 \%$ de todos os funcionários dessas empresas e identificou a adaptabilidade nas três empresas pesquisadas. A adaptabilidade é uma das características da empresa, que afeta a cultura corporativa através da gestão do conhecimento. Transformar o conhecimento em habilidades é um pré-requisito para o sucesso futuro da empresa, reflete em um funcionamento mais eficaz do negócio, bem como um aumento da competitividade. Transformar o conhecimento em negócios representa um pré-requisito para a introdução de mudanças, inovação e criatividade, capital humano, garantindo o processo de crescimento do negócio, na qual a empresa não permanece parada. A análise demonstrou a capacidade das empresas de se adaptar às mudanças no ambiente externo, incluindo a capacidade de responder oportunamente às necessidades e exigências dos clientes em um ambiente competitivo, adaptabilidade na área pelo uso de tecnologias, o uso do conhecimento como pré-requisito para a inovação em vários campos do negócio (produção, liderança, etc.), e a capacidade de eliminar sua incapacidade através do uso efetivo do conhecimento. 
Sanjar e Ali (2014) apresentaram uma investigação empírica para determinar fatores importantes que influenciavam a cultura organizacional na indústria de alimentos. O estudo proposto adaptou um questionário com base nas dimensões da cultura organizacional de Denison e distribui-o entre diferentes grupos de funcionários que trabalhavam para um fabricante de alimentos iraniano na cidade de Zahedan, no Irã. Os resultados indicaram que as dimensões de envolvimento (3.31) e adaptabilidade (3.16) estão em melhor posição em comparação com as dimensões de consistência (3.14) e missão (3.11). O estudo não encontra nenhuma diferença de significância entre o foco interno e externo, o que significa dizer que a organização prestou atenção suficiente aos assuntos internos e externos.

Glaser (2014) realizou um estudo com o objetivo de examinar se a idade organizacional moderava as relações entre o retorno de ativos de uma empresa e os 4 traços de cultura organizacional modelo Denison: missão, consistência, adaptabilidade e envolvimento. Um arquivo com um conjunto de dados composto por 137 organizações de várias indústrias e locais geográficos foi obtido da Denison Consulting. E foram incluídos neste conjunto de dados as seguintes variáveis para cada organização: a idade, o retorno sobre os ativos e as respostas dos funcionários ao questionário sobre a Cultura Organizacional de Denison. Foram observadas relações estatisticamente significativas entre missão, envolvimento e consistência e o desempenho financeiro. Não foi encontrada uma relação estatisticamente significativa entre a adaptabilidade e o retorno de ativos. No entanto, não foi encontrado um efeito moderador estatisticamente significativo da idade organizacional sobre a relação entre qualquer um dos quatro traços da cultura e o retorno sobre os ativos.

Tedla (2016) realizou um estudo de caso com o objetivo de explorar estratégias bem-sucedidas utilizadas por um grupo corporativo na Etiópia para estabelecer uma cultura organizacional efetiva para melhorar o desempenho. $O$ modelo de cultura organizacional de Denison serviu de quadro conceitual para o estudo. Uma amostra intencional de 20 gerentes seniores do grupo participou de entrevistas presenciais semiestruturadas. Descobriu-se que missão e visão bem definidas, (b) alinhamento dos principais valores corporativos, (c) liderança focada nos funcionários e (d) consistência são as melhores estratégias utilizadas para estabelecer uma cultura organizacional eficaz e melhorar o desempenho no grupo estudado. 


\section{4.}

\section{Desempenho organizacional}

Para analisarmos a relação entre cultura organizacional e desempenho empresarial é preciso conceituar o que é desempenho e suas diferentes formas de mensuração.

Barney (2002) define desempenho como o valor gerado por uma organização, comparando-o com o valor possível de se obter em alternativas de investimento existentes no mercado.

Apresenta um segundo conceito em que o desempenho é a visão de múltiplos stakeholders, sendo medido conforme as preferências e desejos destes stakeholders, que incluem os detentores de ações e/ou proprietários da empresa, seus funcionários, a administração da empresa, os detentores de dívida da empresa, fornecedores, parceiros, clientes, governo e a sociedade em geral, levando a diferentes e até conflitantes medidas sobre o desempenho de uma mesma organização - medidas de desempenho financeiro, comumente associadas aos proprietários (detentores de ações), medidas de retorno das dívidas, associadas aos detentores de dívidas, medidas de qualidade e preços de produtos e serviços, associadas aos clientes, medidas de impostos pagos e recolhidos, associadas ao governo e medidas de retorno e responsabilidade social, associadas a ações comunitárias, culturais e educacionais, que beneficiam a sociedade como um todo.

Temos ainda, como outras medidas de desempenho, a própria sobrevivência da organização ao longo do tempo, além das tradicionais medidas contábeis, que podem ser simples, ou então sofrerem ajustes para adequá-las a fatores como tempo, sazonalidade, comportamento da indústria ou setor e alterações nos próprios critérios de medidas.

Neste caso, para analisarmos a relação entre cultura e desempenho como proposto no The Denison Organizational Culture Model - DOCS (DENISON, 1990), daremos foco em alguns dos índices de rentabilidade. Segundo Brigham e Ehrhardt (2015), a rentabilidade é o resultado líquido de um conjunto de políticas e decisões, demonstram os efeitos combinados de liquidez, gestão de ativos e dividas sobre resultados operacionais e nos fornecem dados importantes sobre a eficácia das operações de uma empresa. 
Desta forma os principais indicadores utilizados referem-se a medidas associadas ao balanço patrimonial da empresa, sua demonstração de resultado e os principais índices relacionados a estes demonstrativos, como Return on Sales (ROS), Return on Assets (ROA) e Retorno sobre Patrimônio Líquido (ROE).

\subsection{1.}

\section{Desempenho financeiro}

O desempenho financeiro de uma organização pode ser medido por diversos indicadores, a maior parte deles ligados a dados constantes em suas demonstrações financeiras.

Segundo Brigham e Ehrhardt (2015), os administradores usam analises financeiras para identificar situações que precisam de atenção, credores potenciais usam analises financeiras para determinar se uma empresa tem credibilidade e acionistas utilizam analises financeiras para ajudar a prever futuros resultados, dividendos e fluxo de caixa livre. A análise de demonstrações financeiras envolve também a comparação do desempenho de uma empresa com outras da mesma indústria e avalia as tendências da posição patrimonial e financeira da empresa ao longo do tempo.

Segundo Barney (1986), na microeconomia, o desempenho financeiro das empresas é dividido em três categorias: desempenho normal, desempenho superior e desempenho abaixo do normal. O desempenho econômico é normal quando essa taxa de retorno sobre os investimentos de uma empresa é apenas grande o suficiente para manter os ativos de uma empresa envolvidos em suas atividades atuais (HIRSHLEIFER, 1980). Usando a linguagem da teoria da organização (MCKELVEY, 1982), um retorno normal é um retorno apenas grande o suficiente para garantir a sobrevivência de uma empresa. Tecnicamente, um retorno normal é a taxa esperada de retorno de uma empresa em mercados perfeitamente competitivos (COPELAND e WESTON, 1979). O desempenho financeiro superior é uma taxa de retorno maior do que um retorno normal e indica que uma empresa está prosperando. $O$ desempenho financeiro abaixo do normal é uma taxa de retorno insuficiente para manter os ativos de uma empresa envolvidos em suas atividades atuais. As empresas que obtêm esse nível de retorno por um período de tempo relativamente longo tipicamente não sobrevivem (MCKELVEY, 1982). 


\subsubsection{1.}

\section{Return on Sales (ROS)}

O Return on Sales (ROS) trata da relação entre renda e vendas e compara o lucro com as vendas líquidas (vendas brutas reduzidas por descontos em dinheiro, descontos comerciais, vendas devolvidas e outras provisões). É representado pela fórmula: ROS = renda / vendas. É um bom indicador da eficiência das operações da empresa.

Para este estudo, levando em conta o mercado que está em análise (segurador), será usado o resultado do faturamento como representante do resultado de vendas. O faturamento é composto por: prêmios emitidos + contribuições para cobertura de riscos + resultado com resseguro + rendas de contribuições e prêmios - planos de aposentadoria + rendas com taxa de gestão e outras taxas.

\subsubsection{2.}

\section{Return on Assets (ROA)}

O Return on total Assets (ROA) é o índice de lucro líquido e ativo total e mede o retorno sobre ativo total após juros e impostos. Também chamado de retorno sobre ativos, este indicador é calculado dividindo-se o lucro líquido disponível para acionistas ordinários pelo ativo total. É representado pela fórmula: $\mathrm{ROA}$ = renda / ativos. Esta é uma medida de desempenho comercial tradicional e mede o retorno que uma empresa gera em capital investido.

O ROA mede a velocidade com que uma empresa transforma ativos em vendas e, portanto, em dinheiro e é a verdadeira medida da eficiência da gestão de uma empresa.

\subsubsection{3.}

\section{Retorno sobre Patrimônio Líquido (ROE)}

Nos estudos realizados por Denison, o indicador utilizado foi o Return on Investment (ROI), que se baseia em uma fórmula em que todos os rendimentos são considerados em relação a todos os investimentos, incluindo participação minoritária e dívida de longo prazo.

Para este estudo de caso, este indicador foi substituído pelo ROE, mais comum e disponível nas análises do resultado do mercado segurador e que também é um critério do sucesso do investidor. 
O Retorno sobre Patrimônio Líquido (ROE) é o índice de lucro líquido e patrimônio líquido e mede o retorno sobre patrimônio líquido (return on common equity - ROE). É representado pela fórmula: ROE = Lucro Líquido/Patrimônio Líquido.

O ROE indica se os acionistas estão tendo sucesso, do ponto de vista contábil, em obter retorno sobre seu dinheiro investido. 


\section{3 \\ Metodologia}

\section{1. Tipo de pesquisa}

Este estudo utilizou a abordagem qualitativa, entendendo que este é um meio para explorar e entender o significado que os indivíduos ou grupos atribuem a um problema social ou humano. Este processo de pesquisa envolve as questões e os procedimentos que emergem, os dados tipicamente coletados no ambiente do participante, a análise dos dados indutivamente construída a partir das particularidades para os temas gerais e as interpretações feitas pelo pesquisador acerca do significado dos dados (CRESWELL, 2010). Contudo, algumas análises quantitativas simples serão utilizadas de forma complementar.

Este estudo foi classificado como um estudo analítico porque envolveu o estudo e avaliação aprofundados de informações disponíveis na tentativa de explicar o contexto de um fenômeno e descritivo, por ter se proposto a investigar as características de um fenômeno (a cultura da empresa em questão) e estabelecer correlações entre variáveis (relacionamento entre cultura e desempenho organizacionais).

A estratégia de investigação foi o estudo de caso, dado que o pesquisador explorou profundamente um programa, um evento, uma atividade, um processo ou um ou mais indivíduos. Os casos são relacionados pelo tempo e pela atividade, e o pesquisador coleta informações detalhadas usando vários procedimentos de coleta de dados durante um período de tempo (CRESWELL, 2010). Yin (2005) menciona que o estudo de caso enfrenta uma situação tecnicamente única, uma vez que há muito mais variáveis de interesse do que pontos de dados, além de várias fontes de evidências produzindo dados convergentes. 
Para a realização do estudo foi feita a análise documental das informações disponíveis sobre e na empresa pesquisada, além de ter sido aplicado um questionário individualizado com a média e alta liderança para avaliar sua percepção da cultura organizacional.

Este estudo está circunscrito a uma empresa e tem caráter de profundidade e detalhamento.

Por fim, cabe comentar a atuação do pesquisador como participante no estudo, por trabalhar na área de Recursos Humanos da empresa pesquisada. Este fato pode ajudar na coleta de dados, mas pode gerar uma falta de distanciamento na análise, bem como interferir indiretamente na forma como os questionários foram respondidos. Para minimizar este ponto, não houve a identificação dos respondentes no questionário.

\section{2.}

\section{Universo e amostra}

O universo, nesta pesquisa, é o grupo de gestores da empresa e a amostra, o número de gestores-participantes.

Este grupo consiste em 122 gestores e, destes, 55 responderam ao questionário, num total de $45 \%$ do quadro disponível. A seguir, o detalhamento dos respondentes:

\begin{tabular}{l|r|r}
\hline Demografia & $n$ & $\%$ da amostra \\
\hline Nível hierárquico & \multicolumn{2}{c}{} \\
\hline VP/Diretor & 10 & $18 \%$ \\
Superintendente/Gerente & 45 & $82 \%$ \\
\hline Tempo de casa (em anos completos) & & \\
\hline 0 a 5 anos & 20 & $36 \%$ \\
6 a 10 anos & 14 & $25 \%$ \\
11 a 15 anos & 8 & $15 \%$ \\
16 a 20 anos & 7 & $13 \%$ \\
21 a 25 anos & 5 & $9 \%$ \\
Não respondeu & 1 & $2 \%$ \\
\hline Idade (em anos completos) & & \\
\hline 22 a 37 anos & 11 & $20 \%$ \\
38 a 56 anos & 40 & $73 \%$ \\
57 a 71 anos & 3 & $5 \%$ \\
72 a 89 anos & 1 & $2 \%$ \\
\hline Gênero (masculino, feminino) & \multicolumn{3}{|c}{} \\
\hline Masculino & 37 \\
Feminino & 18 & $33 \%$ \\
Tabela 1 - Dados da amostra &
\end{tabular}


A EMPRESA $X$ é a maior seguradora independente do Brasil nos setores em que atua, sua matriz localiza-se no Rio de Janeiro e sua escolha foi baseada prioritariamente devido a fatores de acessibilidade e conveniência.

Neste trabalho, tem-se o intuito de explorar um caso particular e específico, mas com características bem interessantes e particulares, que irão auxiliar a compreensão da relação entre cultura e desempenho. $E$ além de objetivos acadêmicos, tem como objetivos práticos, favorecer a tomada de decisão, planejamento e possível mudança organizacional.

Neste trabalho, não se busca generalizar dados desta empresa para todo o setor, nem para outras indústrias.

\section{3.}

\section{Seleção dos sujeitos}

Os sujeitos da pesquisa são aqueles que participaram fornecendo informações necessárias ao desenvolvimento da análise. A empresa possui atualmente um quadro de aproximadamente 1500 funcionários, mas o questionário realizado teve como alvo o seu quadro gerencial (diretores e gerentes de primeira linha.

O critério para a seleção do grupo baseou-se em acessibilidade e a restrição ao grupo gerencial, foi motivada pela intenção de se obter informações estruturadas acerca da cultura organizacional envolvidas no estudo. Gordon (1992) menciona que a limitação da investigação cultural ao nível gerencial da empresa apresenta vantagens e desvantagens. Ao mesmo tempo em que os gerentes podem não representar uma amostra relevante para a análise - além de normalmente apresentarem um viés mais positivo sobre a empresa quando comparado com os demais empregados - é neste nível que a cultura muitas vezes é criada e alterada através dos fundadores, líderes e pessoas influentes (SCHEIN, 2004).

\section{4. \\ Procedimentos e instrumentos de coleta de dados}

$\mathrm{Na}$ pesquisa documental, foram levantados dados referentes ao setor de atuação da empresa, além de seu histórico, sua representatividade no setor de atuação e os valores desejados pela empresa. Esta pesquisa foi realizada na internet, em relatórios internos da empresa e em relatórios de pesquisa pertinentes ao assunto. 
Para avaliação da cultura organizacional, buscou-se informações na internet da empresa estudada e para os traços culturais, foi utilizado o questionário desenvolvido por Denison (1990) que sustenta que a vinculação das práticas de gestão com os pressupostos e crenças subjacentes da organização é importante para o estudo da relação entre cultura e eficácia. Este questionário possui 60 afirmativas que são agrupadas em 12 subdimensões e em 4 dimensões. Para cada afirmativa, o participante foi orientado a marcar, numa escala do tipo "Likert" de 1 a 5, onde o discordo totalmente se referia a nota 1 e o concordo totalmente a nota 5 sua percepção da pratica na empresa pesquisada.

Para avaliação dos indicadores Return on Sales (ROS), Return on Assets (ROA) e Retorno sobre Patrimônio Líquido (ROE), escolhidos como parâmetros do desempenho e eficácia organizacionais baseados no resultado financeiro, foram coletadas informações no balanço patrimonial e demonstrações financeiras e também nos relatórios gerenciais disponíveis na área financeira da empresa em dezembro de 2017. Estes dados são atualizados constantemente para envio a SUSEP.

\section{5 .}

\section{Tratamento dos dados}

Pela análise dos dados oriundos do questionário, foi possível captar a percepção das práticas e traços culturais da empresa pesquisada.

Através de uma análise interpretativa dos dados, procurou-se verificar padrões que pudessem auxiliar no entendimento da cultura da empresa, sem a pretensão de se realizar generalizações a partir destas análises.

Os resultados representam indícios e as informações quantitativas que porventura são utilizadas não pretendem proporcionar conclusões determinísticas, mas sim suportar a análise dos dados.

\section{6.}

\section{Limitações do método}

Sobre a metodologia de estudo de caso único, uma das principais limitações é que não poderão ser realizadas generalizações estatísticas dos resultados encontrados, apenas generalizações analíticas. Além disso, Yin (2001) coloca ainda uma limitação adicional quando se trata de um estudo de caso único. Apesar de ser adequado em muitas situações, a vulnerabilidade potencial deste tipo de pesquisa é que o caso pode, mais tarde acabar não sendo o caso que se imaginava a princípio, não tendo as características que se julgam necessárias para que ele seja suficiente por si só. 
Além destas limitações, temos ainda as seguintes dificuldades com relação a coleta, tratamento e análise dos dados:

a) as informações coletadas e utilizadas para a análise cultural da empresa em questão decorrem de percepções dos participantes, que são naturalmente subjetivas e sujeitas a possíveis distorções;

b) há pouca profundidade no estudo da estrutura e dos processos sociais - levantamentos possibilitam obter grande volume de dados sobre os indivíduos, no entanto, como os fenômenos sociais são determinados em sua maior parte por fatores interpessoais e institucionais, os levantamentos são pouco adequados a investigação profunda desses fenômenos (GIL, 1991);

c) por se tratar de uma pesquisa qualitativa, não existe um processo fechado de sistematização, podendo impactar na interpretação dos resultados pelo pesquisador. 


\section{Descrição e análise dos resultados}

4.1.

\section{A empresa}

A empresa objeto deste estudo faz parte do Grupo X, que conta com a vasta experiência de seus fundadores, ligados ao mercado segurador e de capitais no Brasil desde 1935. Fundada na década de 90, foi a primeira seguradora especializada em Seguros de Vida e planos de Previdência complementar no Brasil. Está entre as maiores seguradoras independentes do Brasil em Vida, Previdência e Capitalização e é especialista em oferecer soluções de proteção e planejamento financeiro para cada fase da vida.

Presente em todas as capitais nacionais, com mais de 30 filiais, distribui seus produtos por meio de uma rede de mais de 200 parceiros comerciais e 4 mil corretores. Possui aprox. 50 mil empresas que utilizam seus produtos como benefícios para seus funcionários e mais de 5 milhões de clientes. Dispõe de mais de 100 fundos sob sua gestão para investimento e os recursos somam mais de $R \$ 23$ bilhões.

Desde a sua fundação, a empresa cultiva em seu DNA valores e compromissos que vão muito além do aspecto financeiro e apoia diversas iniciativas voltadas para a sustentabilidade e a responsabilidade social:

Saúde - apoia instituições importantes, como o Instituto Ronald McDonald, a Operação Sorriso e Médicos sem Fronteiras, dentre tantos outros, que ajudam a melhorar a saúde e a qualidade de vida de milhares de pessoas ao redor do mundo, possibilitando um futuro com mais felicidade e dignidade. Promover a saúde é uma forma de mostrar o seu compromisso com a vida, com as pessoas e com o bem-estar.

Educação e Profissionalização - apoia projetos que contribuem com a formação de crianças e jovens, promovendo a inclusão e o acesso à educação de qualidade como o Instituto Pró Saber, o Bola para a Frente e o projeto social da Mangueira. A empresa acredita que quanto mais acesso à Educação as pessoas tiverem, mais terão consciência sobre a importância de se planejar e se proteger em longo prazo. E essa visão gera um enorme impacto em toda a sociedade. 
Esporte - apoia projetos como o Instituto Reação, o Instituto Superar e o projeto Bons Ventos. No Esporte ou na vida financeira valores como disciplina, trabalho de equipe, técnica, proteção, preparo, persistência e visão de longo prazo sempre se fazem presentes.

Cultura - esteve ao lado de grandes ícones da MPB, como Edu Lobo, Maria Bethânia, Chico Buarque entre outros, como forma de investir e incentivar a cultura nacional, com principal foco na música.

Ao longo dos anos, recebeu prêmios e participou dos mais importantes rankings financeiros nacionais, reunindo certificações que reforçam a credibilidade, o desempenho e a excelência em sua gestão.

\subsection{1. \\ Sua história}

Na década de 90, o Grupo X cria a EMPRESA X: empresa especializada em seguros de vida e planos de previdência.

Ainda nesta década, associa-se à um parceiro internacional e torna-se, também, representante exclusiva de uma importante rede internacional de Seguro de Vida no Brasil.

Em 2004, lança sua administradora de recursos e em 2005, adquire tanto uma seguradora especializada em Vida e Previdência quanto a carteira de vida e previdência de outra seguradora, além de trazer para o Brasil a tecnologia de um fundo especifico de ciclo de vida.

Em 2006 ocupa o primeiro lugar entre as seguradoras independentes, no ranking total do seu mercado de atuação, posição que pertence a empresa até os dias de hoje. Recebe a classificação MQ2 da Agência Moody's.

Em 2007, recebe o prêmio de Melhor Gestora de Previdência por seu desempenho em 2006, e torna-se a primeira seguradora a ter a Central de Relacionamento com o Cliente certificada com o Selo de Ética Probare.

Em 2008, recebe pelo segundo ano consecutivo o prêmio de Melhor Gestora de Previdência e pela segunda vez recebe o Selo de Ética Probare.

Em 2009, registra lucro líquido recorde e a seguradora é posicionada como a $4^{\text {a }}$ empresa mais admirada do mercado segurador por uma pesquisa promovida pela Carta Capital.

Em 2010, é anunciada a compra da totalidade das ações do parceiro internacional e a Moody's reafirma o rating MQ2 para a sua administradora de recursos. 
Em 2011, a empresa é a primeira seguradora com Call Center próprio a ser certificada pela Norma de Maturidade de Gestão do PROBARE. Além de receber o prêmio Top Consumidor 2011, concedido pela revista Consumidor Teste, em parceria com o Instituto Nacional de Educação do Consumidor e do Cidadão (INEC), na categoria Excelência nas Relações de Consumo e Respeito ao Meio Ambiente.

Em 2012, a empresa foi vencedora do Top de Marketing ADVB/RS 2012 na categoria 'Seguros'.

Em 2013, fica entre as cinco melhores seguradoras mundiais no ranking da revista Época Negócios $360^{\circ}$, conquistando a primeira colocação nas categorias: governança, inovação, finanças e visão de futuro.

Em 2014, fica entre as 10 melhores empresas de Vida e Previdência do mercado brasileiro no ranking da Valor 1000, o anuário de análises de empresas do mercado brasileiro e recebe o prêmio de Destaques do ano 2013, na categoria Seguros, do Jornal do Comércio. Conquista o Prêmio Antônio Carlos de Almeida Braga de Inovação de Seguros da Cnseg na categoria Comunicação, ganha o selo da ADVB-RS na categoria Comunicação e o 1ํo lugar no Prêmio Top de Marketing ADVB/RS na Categoria Seguros.

Em 2015, fica entre as cinco melhores seguradoras do Brasil no ranking da revista Época Negócios $360^{\circ}$ e ganha o prêmio de Best Fund Manager Brazil pela publicação londrina Internacional Finance Magazine. Conquista pelo segundo ano consecutivo o Prêmio Antônio Carlos de Almeida Braga de Inovação de Seguros da Cnseg na categoria Comunicação e mais uma vez fica em 1ำ lugar no Prêmio Top de Marketing ADVB/RS na Categoria Seguros. É eleita pelos funcionários como uma das melhores empresas para trabalhar no Brasil no ranking do Great Place to Work.

Em 2016, conquista pelo 3ํano consecutivo o Prêmio Antônio Carlos de Almeida Braga de Inovação de Seguros da Cnseg na categoria Comunicação e é novamente eleita pelos funcionários como uma das melhores empresas para trabalhar no Brasil no ranking do Great Place to Work.

Em 2017, fica entre as Melhores Seguradoras segundo a Revista Época Negócios $360^{\circ}$ e é eleita pela $3^{\underline{a}}$ vez consecutiva como uma das melhores empresas para trabalhar no Brasil no ranking do Great Place to Work. Alcança o 1 이a luar no ranking de portabilidade líquida. 


\section{2.}

\section{A cultura organizacional da EMPRESA X}

Esta seção apresentará e analisará os traços culturais a partir do resultado encontrado na aplicação do questionário desenvolvido por Denison (1990) que sustenta que a vinculação das práticas de gestão com os pressupostos e crenças subjacentes da organização é importante para o estudo da relação entre cultura e desempenho.

Será dividida em 11 seções, sendo a primeira uma visão geral do resultado encontrado em todas as dimensões e subdimensões que compõem o modelo.

Da seção 2 até a seção 5 serão apresentados e analisados os resultados das dimensões separadamente - Missão, Consistência, Envolvimento e Adaptabilidade.

Nas seções 6 a 11 serão apresentadas e analisadas as diferentes tensões existentes quando as organizações tentam alcançar a integração interna e a adaptação externa.

\subsection{1.}

\section{Visão geral}

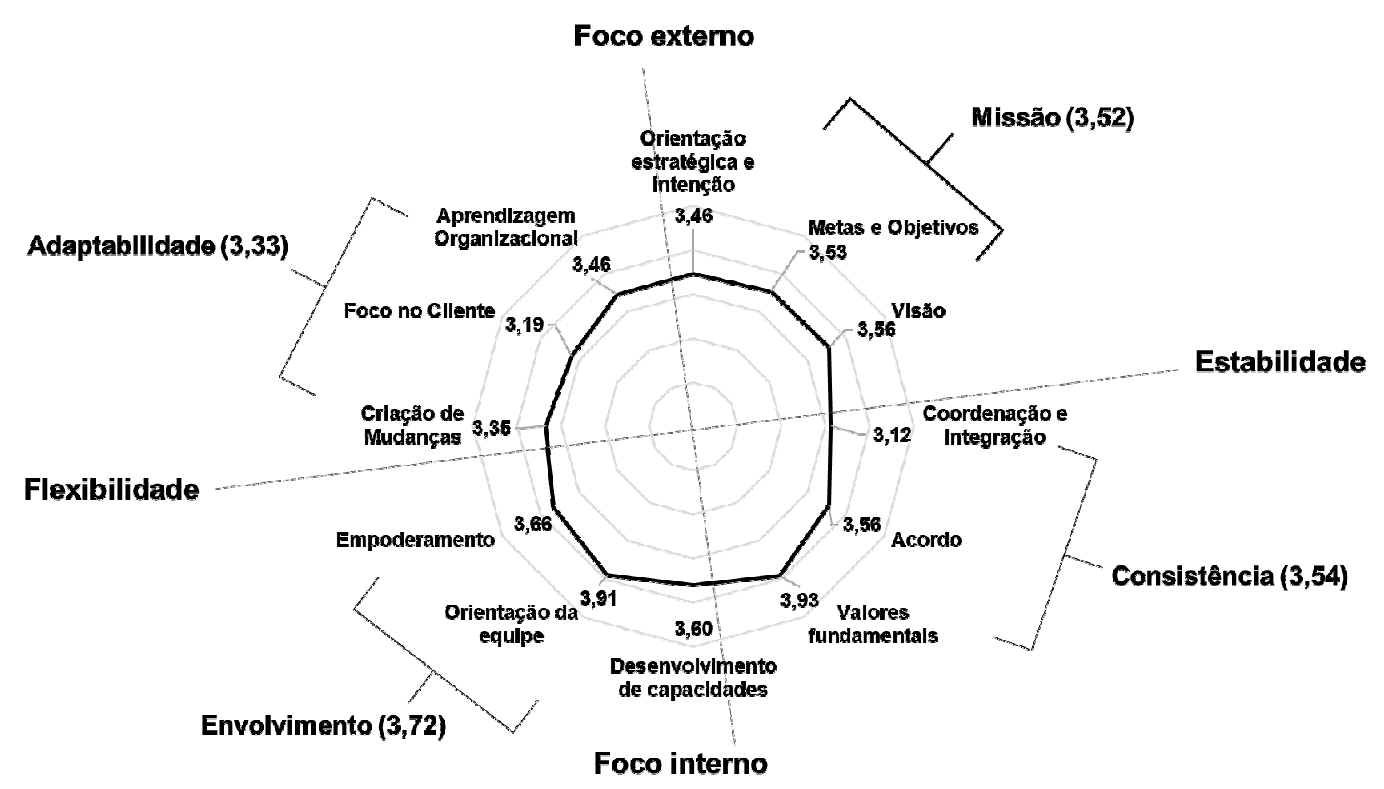

Figura 2 - Resultado geral da Pesquisa de Cultura

$\mathrm{Na}$ visão geral do resultado, observa-se que a média das dimensões culturais - Missão, Consistência, Envolvimento e Adaptabilidade estão com resultados bem distribuídos e próximos (desvio padrão de 0,16 ). A pesquisa de Denison demonstrou que a cultura de uma organização efetiva deve refletir todas essas dimensões. Assim, as organizações efetivas provavelmente terão culturas 
que são adaptativas, mas altamente consistentes e previsíveis, e que promovam um alto envolvimento, mas fazem isso no contexto de um senso de missão compartilhado.

A pesquisa realizada por Hause (2000) reforça este entendimento. Os resultados reportados mostraram que tanto o nível quanto as medidas de acordo da força da cultura organizacional são preditivas da eficácia organizacional e no estudo realizado por Glaser (2014), foram observadas relações estatisticamente significativas entre missão, envolvimento e consistência e o desempenho financeiro.

Além disso, observamos pela análise do resultado geral, que a organização prestou atenção suficiente aos assuntos internos e externos, assim como no estudo realizado por Sanjar e Ali (2014), onde não se encontrou nenhuma diferença de significância entre o foco interno e externo.

\subsection{2.}

Missão

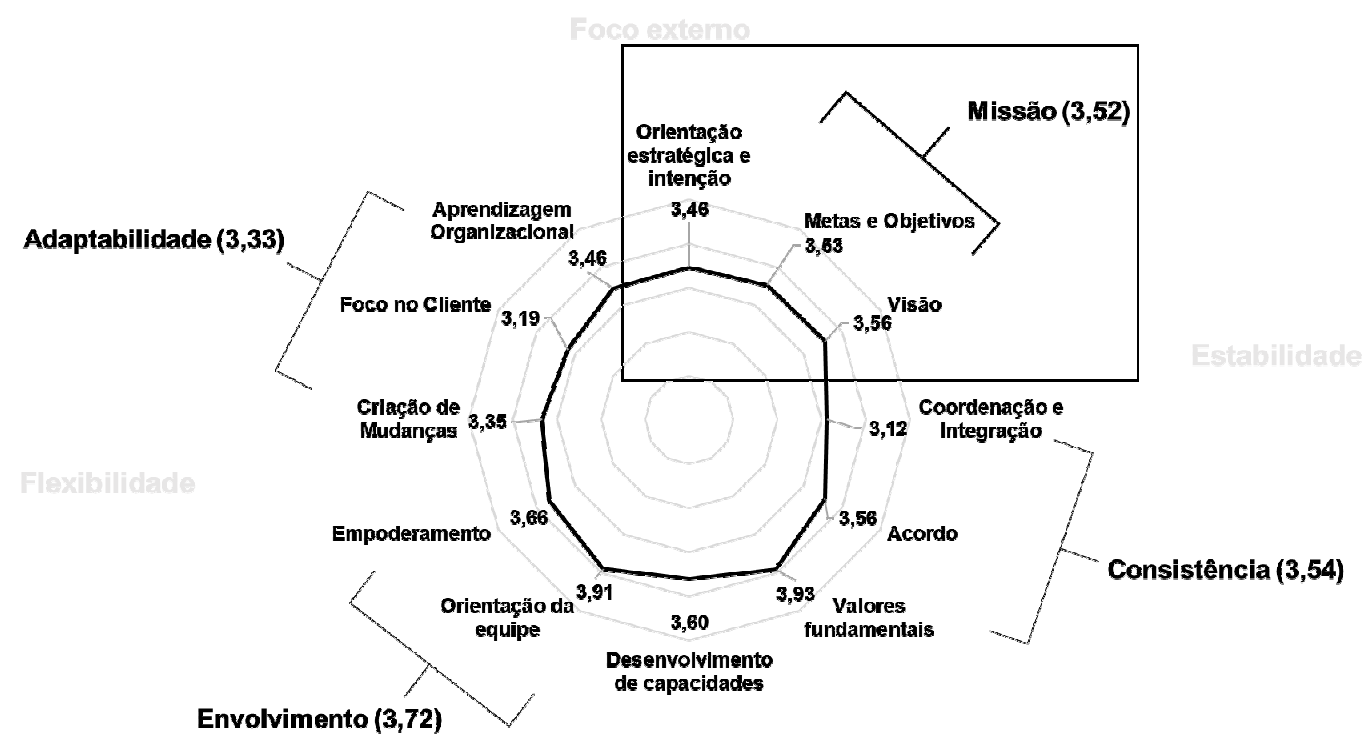

Figura 3 - Resultado Dimensão Missão

O resultado da média da Missão $(3,52)$ pode indicar que há um forte e claro sentido organizacional, o que afeta todas as áreas de atuação, com exceção da inovação no desenvolvimento de produtos. Uma missão fornece propósito e significado, definindo um papel social e objetivos externos para a organização. Ela fornece uma direção clara e metas que servem para definir um curso de ação apropriado para a organização e seus membros. Um senso de missão permite que uma organização dê forma ao comportamento atual visando 
um estado futuro desejado. Ser capaz de internalizar e se identificar com a missão de uma organização contribui para o compromisso a curto e longo prazo com a organização. O sucesso é mais provável quando indivíduos e organizações são direcionados por objetivos.

O estudo que foi realizado por Yilmaz e Ergun (2008) indicam que o traço missão é o mais importante em termos de promover o desempenho global da empresa, assim como o crescimento das vendas, o crescimento da participação de mercado e o retorno sobre ativos.

O estudo realizado por Mario Ernesto (2010) levou a conclusão de que somente o traço missão evidencia relações significativas com algumas medidas de desempenho.

Tedla (2016) identificou que missão e visão bem definidas, (b) alinhamento dos principais valores corporativos, (c) liderança focada nos funcionários e (d) consistência são as melhores estratégias utilizadas para estabelecer uma cultura organizacional eficaz e melhorar o desempenho.

Sobre o resultado da média da subdimensão Orientação estratégica e intenção $(3,46)$, pode-se entender que as intenções estratégicas são claras e transmitem o propósito da organização e deixam claro como todos podem contribuir e "construir a marca" na indústria.

Sobre o resultado da média da subdimensão Metas e objetivos $(3,53)$, pode-se dizer que a organização tem um conjunto claro de metas e objetivos vinculado à missão, visão e estratégia, e fornece a todos uma direção clara em seu trabalho.

Sobre o resultado da média da subdimensão Visão $(3,56)$, pode-se entender que a organização possui uma visão compartilhada de um estado futuro desejado. Ela incorpora valores fundamentais e captura os corações e as mentes das pessoas, ao mesmo tempo que fornece orientação e direção.

Considerando-se que o resultado de destaque é Visão, pode-se entender também que:

- A empresa tem uma visão compartilhada sobre o que será no futuro;

- Que os líderes nesta organização têm uma orientação a longo prazo;

- Que a Visão cria emoção e motivação para os funcionários;

- Que é possível atender a demanda de curto prazo sem comprometer a visão de longo prazo. 


\subsection{3.}

\section{Consistência}

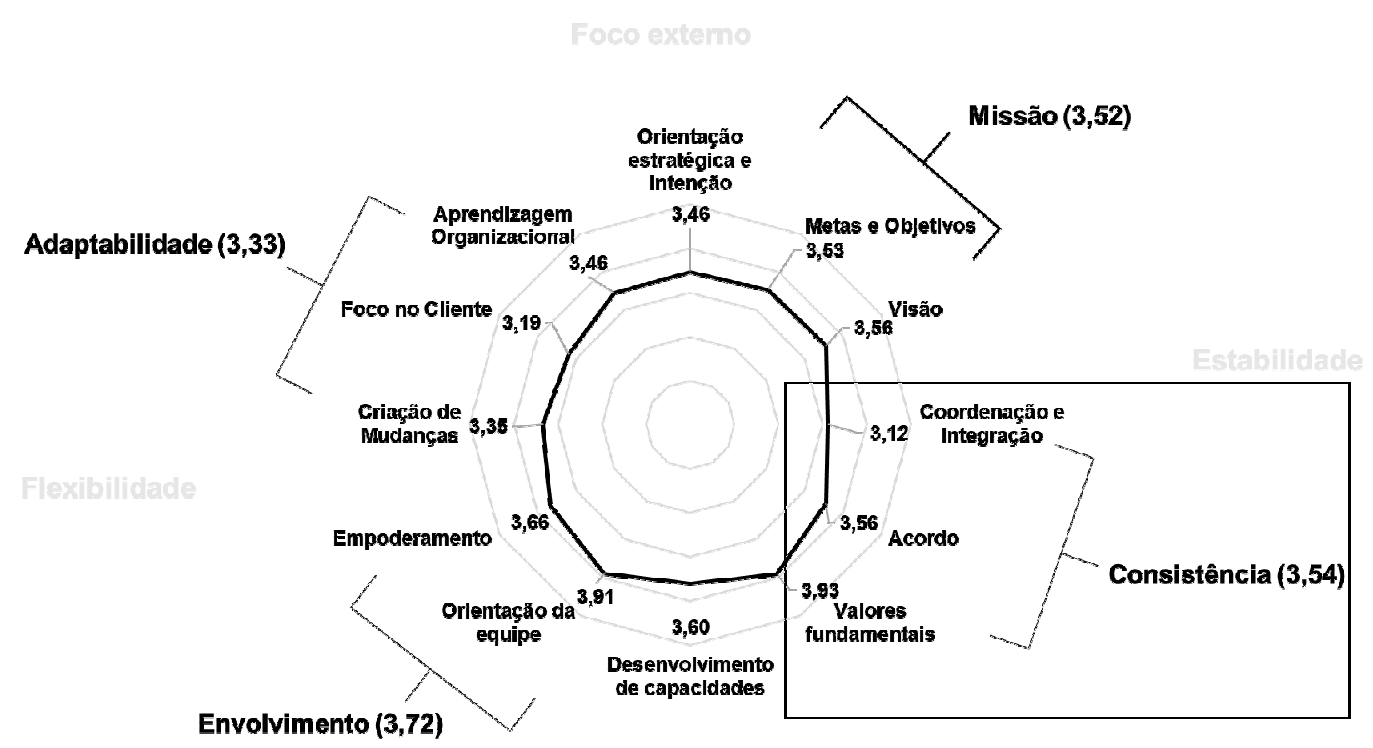

Figura 4 - Resultado Dimensão Consistência

O resultado da média da Consistência $(3,54)$ pode indicar uma cultura "forte", baseada em um sistema compartilhado de crenças, valores e símbolos amplamente entendidos pelos membros de uma organização. Neste contexto, sistemas de controle implícitos baseados em valores internalizados podem ser um meio mais eficaz para alcançar coordenação e integração do que sistemas de controle externo que dependam de regras e regulamentos explícitos.

Dentre as dimensões apresentadas no modelo de Denison (The Denison Organizational Culture Model - DOCS, DENISON, 1990), está é a com menor alcance sobre o efeito de curto prazo. Seu principal impacto é na qualidade e na satisfação dos funcionários.

Sobre o resultado da média da subdimensão Coordenação e Integração $(3,12)$, pode-se entender que nem sempre diferentes funções e unidades da organização são capazes de trabalhar bem em conjunto para alcançar metas comuns e que os limites organizacionais podem interferir com o trabalho feito. $E$ ainda que:

- Nem sempre a abordagem para fazer negócios é consistente e previsível;

- Não há necessariamente um bom alinhamento das metas em todos os níveis dessa organização;

- As pessoas de diferentes unidades organizacionais nem sempre compartilham uma perspectiva comum; 
- Pode ser difícil coordenar projetos em unidades funcionais nesta organização;

- Trabalhar com alguém de outra parte desta organização é como trabalhar com alguém de uma empresa diferente.

Sobre o resultado da média da subdimensão Acordo $(3,56)$, pode-se entender que a organização pode chegar a um acordo sobre questões críticas. Isso inclui o nível de concordância subjacente e a capacidade de conciliar as diferenças quando ocorrem.

Sobre o resultado da média da subdimensão Valores fundamentais $(3,93)$, o melhor resultado no questionário, pode-se entender que os membros da organização compartilham um conjunto de valores, criando um senso de identidade e um conjunto claro de expectativas. E ainda que:

- Existe um conjunto de valores claro e consistente nesta empresa que governa a maneira como fazem negócios;

- Esta empresa tem um estilo de gerenciamento característico e um conjunto distinto de práticas de gerenciamento;

- Os gerentes nesta empresa "praticam o que pregam";

- Esta organização possui um código ético que orienta seu comportamento e diz o que é certo e errado;

- Ignorar os valores fundamentais desta organização irá causar problemas.

Considerando que o resultado do Acordo é menor que os Valores Fundamentais, mas maior que Coordenação e Integração, pode-se entender que, por vezes, apesar das boas intenções, a organização torna-se desalinhada por conflitos ou opiniões diferentes. Pode ocorrer que, durante as discussões, todos falem ao mesmo tempo, as pessoas ignorem a contribuição de outros ou se retirem da discussão. A questão é que nada é resolvido e as pessoas continuam a "soprar as mesmas velas" repetidamente. 


\subsection{4.}

\section{Envolvimento}

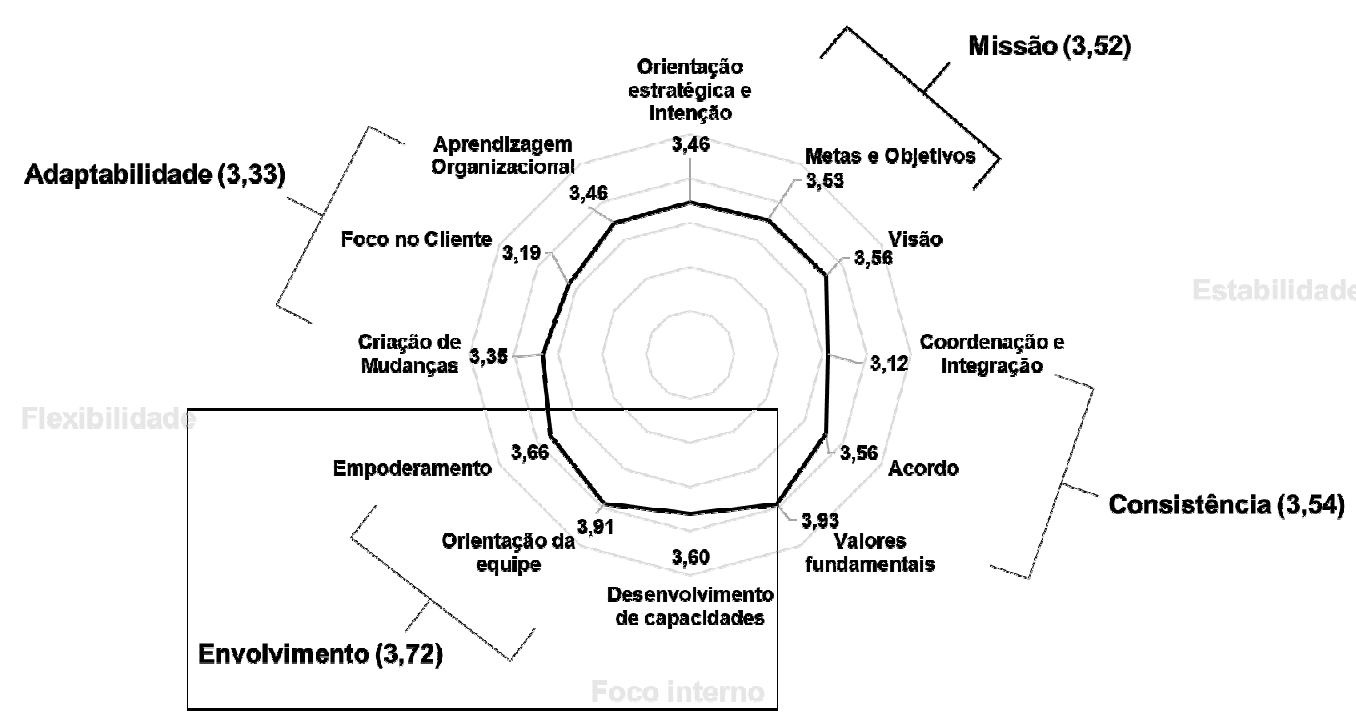

Figura 5 - Resultado Dimensão Envolvimento

O resultado da média do Envolvimento $(3,72)$, a melhor dentre todas as dimensões, nos leva a crer que se trata de uma cultura que incentiva fortemente o envolvimento dos funcionários, criando um senso de propriedade e responsabilidade. Podemos entender também que dependem de sistemas de controle informais, voluntários e implícitos, em vez de sistemas de controle formais, explícitos e burocráticos. Fora desse sentimento de propriedade, cresce um maior compromisso com a organização e uma crescente capacidade de autonomia.

Receber a contribuição dos membros da organização pode aumentar a qualidade das decisões e melhorar a sua implementação. $\mathrm{E} O$ alto envolvimento do empregado também pode afetar o desempenho em todas as áreas, embora seu efeito seja mais fraco para as Receitas de Vendas e Market share.

Sobre o resultado da média da subdimensão Empoderamento $(3,66)$, pode-se entender que os indivíduos têm autoridade, iniciativa e habilidade para gerenciar seu próprio trabalho, o que cria um senso de propriedade e responsabilidade para com a organização.

Sobre o resultado da média da subdimensão Desenvolvimento de capacidade $(3,60)$, pode-se supor que a organização investe continuamente no desenvolvimento das habilidades dos funcionários para se manter competitiva e atender às necessidades do negócio. 
E sobre o resultado da média da subdimensão Orientação de equipe $(3,91)$, pode-se entender que há valor em trabalhar cooperativamente em direção a objetivos comuns para os quais todos se sentem mutuamente responsáveis e ainda que:

- A cooperação e a colaboração entre os papéis funcionais são ativamente encorajadas nessa organização;

- Trabalhar nessa organização é como fazer parte de uma equipe;

- O trabalho é sensivelmente organizado nesta organização para que cada pessoa possa ver a relação entre seu trabalho e os objetivos da organização;

- As equipes são o bloco de construção primário desta organização;

- Esta organização depende de controle horizontal e coordenação para fazer o trabalho, em vez de hierarquia.

Apesar disto, como o resultado da Orientação da equipe $(3,91)$ é maior do que o do Empoderamento $(3,66)$ ou Desenvolvimento de Capacidades $(3,60)$, isto pode ser uma indicação de que talvez não haja muita solidez para o time. As pessoas tendem a ser "batedores de cabeça" e se cumprimentam alegremente sem muito compromisso e propriedade. As equipes em prol da aparência da equipe parecem ser a norma e não parecem fazer a diferença.

\subsection{5.}

\section{Adaptabilidade}

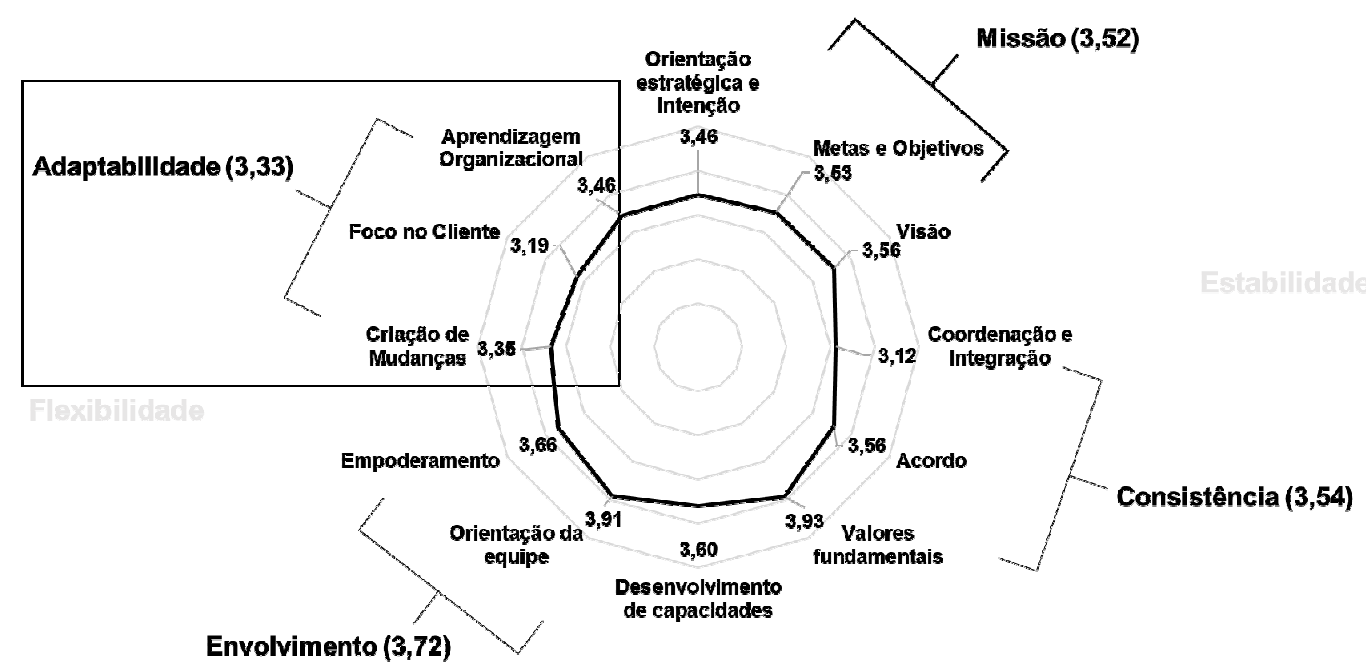

Figura 6 - Resultado Dimensão Adaptabilidade 
O resultado da média da Adaptabilidade $(3,33)$, a menor dentre todas as dimensões do questionário, pode indicar uma pouca capacidade de traduzir as demandas do ambiente empresarial em ação, afetando todas as áreas de atuação, exceto rentabilidade e retorno de ativos.

As organizações que possuem um sistema de normas e crenças que apoiam a capacidade da organização de receber, interpretar e traduzir sinais de seu ambiente para mudanças comportamentais internas aumentam suas chances de sobrevivência, crescimento e desenvolvimento.

O estudo realizado por Turáková e Rečičár (2013) demonstrou a capacidade das empresas pesquisadas de se adaptar às mudanças no ambiente externo, como sua capacidade de responder oportunamente às necessidades e exigências dos clientes em um ambiente competitivo, adaptabilidade na área pelo uso de tecnologias, o uso do conhecimento como pré-requisito para a inovação em vários campos do negócio (produção, liderança, etc.) e a capacidade de eliminar sua incapacidade através do uso efetivo do conhecimento.

Sobre o resultado da média da subdimensão Aprendizagem organizacional $(3,46)$, pode-se entender que a organização recebe, traduz e interpreta os sinais do meio ambiente em oportunidades para incentivar a inovação, ganhar conhecimento e desenvolver capacidades e ainda que:

- Esta organização incentiva a inovação e recompensa aqueles que correm riscos;

- Vê o fracasso como uma oportunidade de aprendizado e melhoria;

- Algumas coisas são negligenciadas ou esquecidas nessa organização;

- O aprendizado é um objetivo importante no trabalho cotidiano;

- Todos sejam informados sobre o que está acontecendo.

Sobre o resultado da média da subdimensão Criação de Mudanças $(3,35)$, pode-se entender que a organização é capaz de criar formas adaptativas para atender às mudanças nas necessidades. É capaz de ler o ambiente de negócios, reagir rapidamente às tendências atuais e antecipar as mudanças futuras.

Sobre o resultado da média da subdimensão Foco no Cliente $(3,19)$, podese entender que a organização nem sempre entende e reage a seus clientes e antecipa suas necessidades futuras. Esta subdimensão reflete o grau em que a organização é conduzida por uma preocupação para satisfazer seus clientes e pode-se esperar que: 
- Os comentários e recomendações dos clientes nem sempre levem a mudanças nessa organização;

- A entrada do cliente pouco influencia ou influencia indiretamente suas decisões;

- Nem todos os membros desta organização têm uma compreensão profunda dos desejos e necessidades dos clientes;

- Não necessariamente o contato direto com os clientes pelos membros da organização é incentivado;

- Os interesses do cliente final são frequentemente ignorados em nossas decisões.

Como o resultado da média da subdimensão Aprendizagem Organizacional $(3,46)$ e da média da subdimensão Criação de Mudanças $(3,35)$ são maiores do que o Foco no Cliente $(3,19)$, a organização pode ser boa em reconhecer as melhores práticas e criar novos padrões na indústria, mas tem dificuldade em aplicar o conhecimento adquirido ao trabalho diário com seus próprios clientes. O conhecimento está dentro da organização, mas, infelizmente, não com os clientes.

\subsection{6.}

\section{Foco externo}

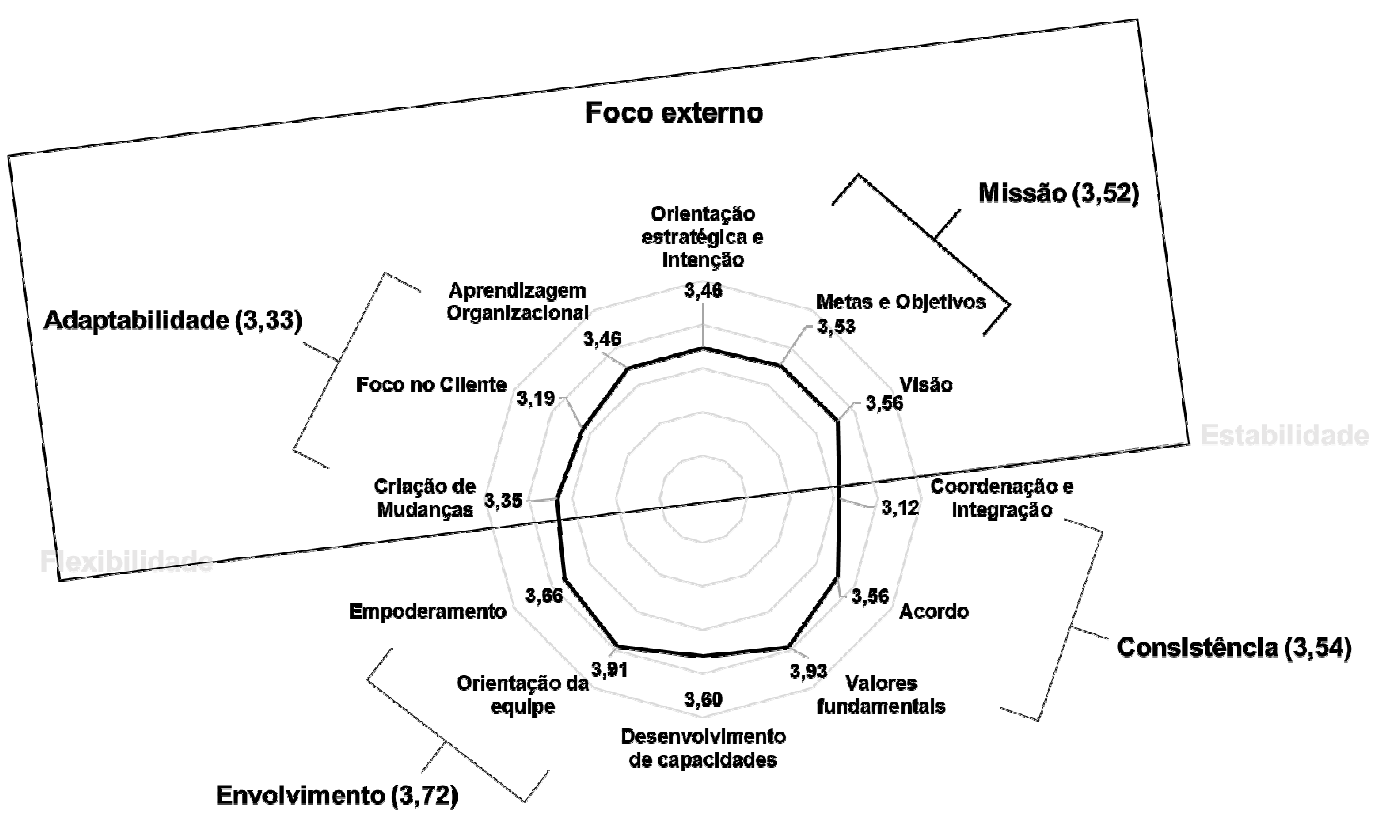

Figura 7 - Resultado Foco Externo 
Adaptabilidade e Missão tomam como foco a relação entre a organização e o ambiente externo. Observa-se que esta organização atua com foco externo forte (adaptabilidade mais missão) e por isso, deve se concentrar na adaptação e mudança em resposta ao ambiente externo. Este resultado geralmente influencia as receitas ou renda, o crescimento das vendas e a participação no mercado.

Cabe comentar que a empresa com foco na alavancagem do ambiente externo, sem foco em sistemas, processos e controles, pode não ter os controles necessários para manter ou gerenciar o crescimento e, eventualmente, experimentar dificuldade em entregar aos clientes.

\subsection{7.}

\section{Foco interno}

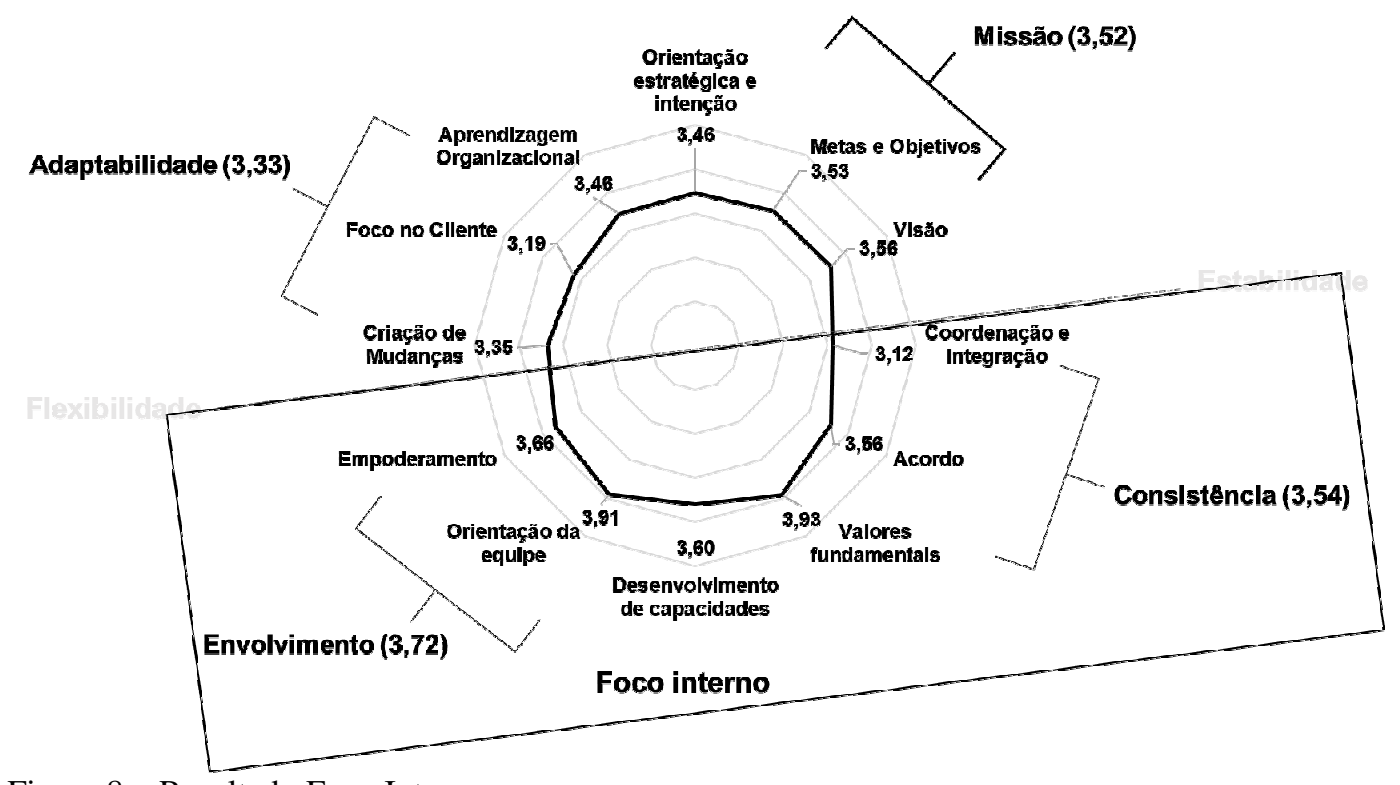

Figura 8 - Resultado Foco Interno

Envolvimento e Consistência abordam a dinâmica interna de uma organização. Observa-se que esta organização tem foco interno forte (envolvimento mais consistência) e por isso, espera-se que se concentre na dinâmica da integração interna de sistemas, estruturas e processos. O resultado destas dimensões afeta a qualidade, a satisfação dos funcionários e o retorno do investimento. Assim, um foco interno forte também está associado a qualidade produtos e serviços, ou seja, com níveis mais altos de qualidade, menos defeitos e menos retrabalho, boa utilização dos recursos e alta satisfação dos funcionários. 


\subsection{8.}

\section{Estabilidade}

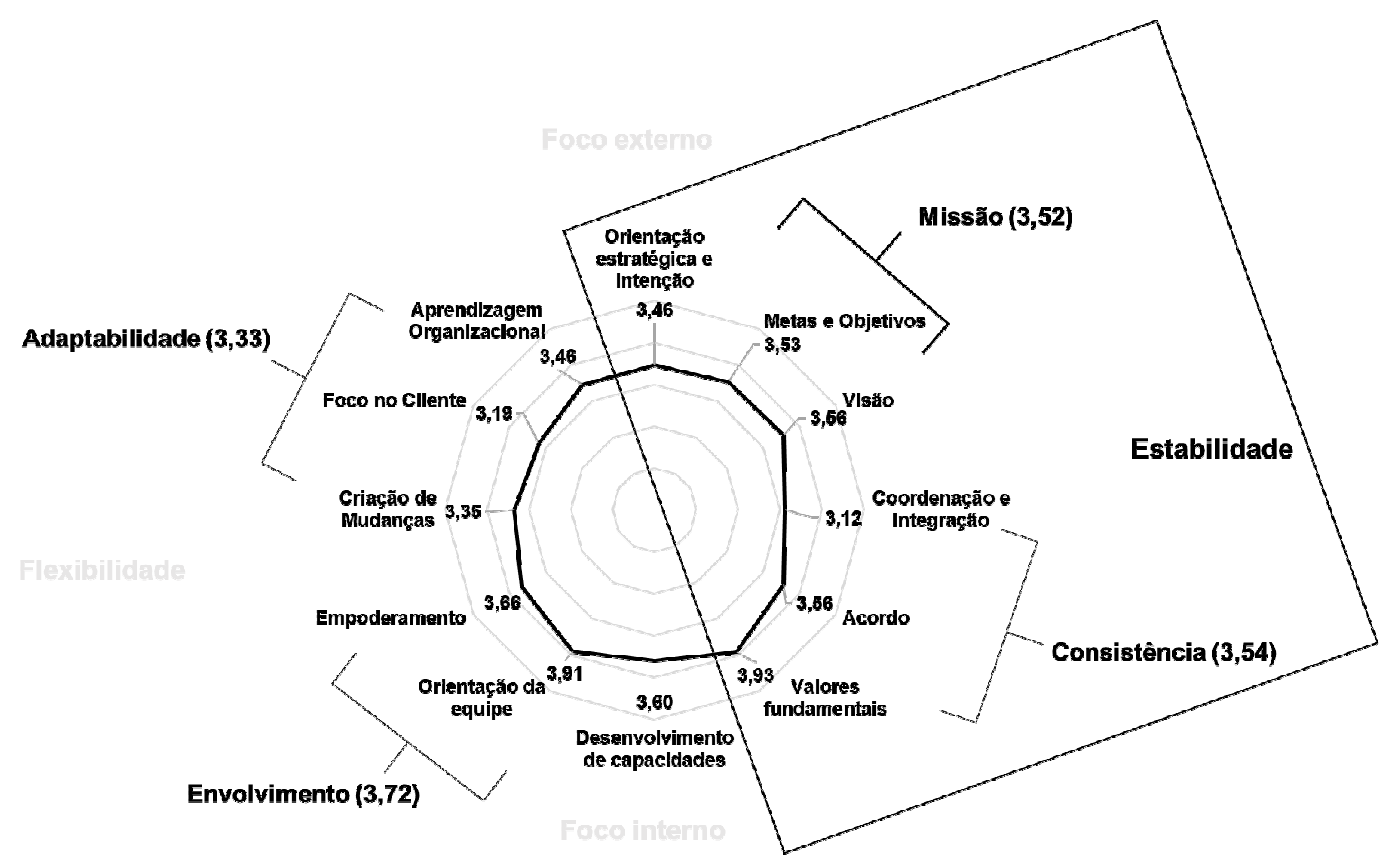

Figura 9 - Resultado Estabilidade

Consistência e a Missão enfatizam a capacidade de estabilidade e direção da organização. O resultado destas dimensões (3,54 e 3,52, respectivamente) pode indicar uma empresa estável, com capacidade de se manter focada e previsível ao longo do tempo, com maior ênfase ao controle e à estabilidade e redução de variedade.

Este resultado pode ser associado a medidas de desempenho financeiro como retorno sobre ativos (ROA), retorno de investimentos (ROI) e retorno de vendas (ROS), bem como operações comerciais fortes. Um resultado alto normalmente indica altos retornos de ativos, investimentos e vendas e força operacional. 


\subsection{9.}

\section{Flexibilidade}

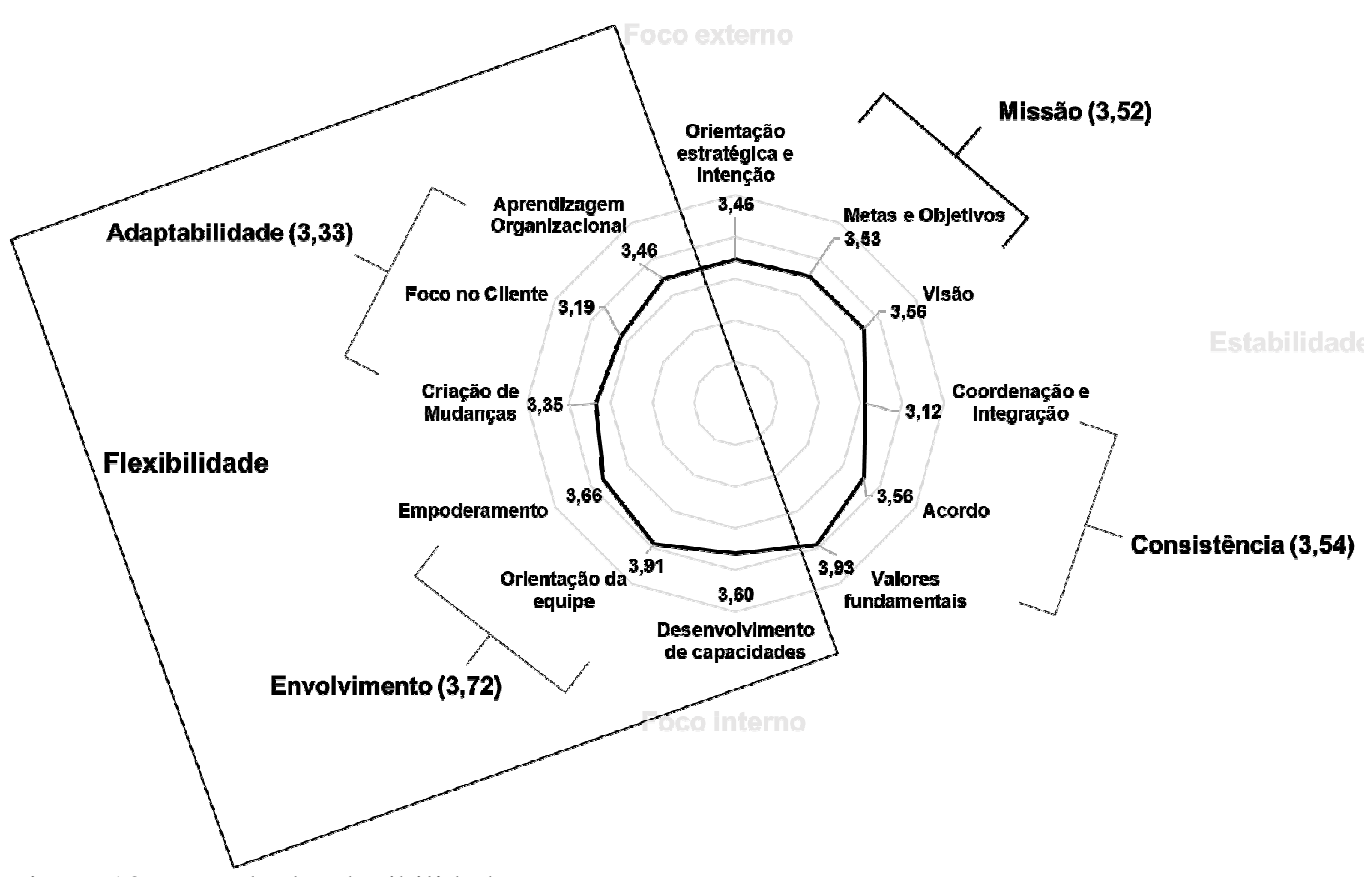

Figura 10 - Resultado Flexibilidade

Envolvimento e Adaptabilidade enfatizam a capacidade de uma organização de flexibilidade e mudança. O resultado pode indicar uma organização flexível (3,72 e 3,33 respectivamente), com capacidade de fazer mudanças em resposta ao meio ambiente, ligada a desenvolvimento de produtos e inovação, ou seja, níveis mais altos de inovação de produtos e serviços, criatividade e uma resposta rápida aos requisitos de mudança de clientes e funcionários. Um sistema orientado para Envolvimento e Adaptabilidade irá introduzir mais variedade, mais insumos e mais possíveis soluções para uma situação dada. 


\subsubsection{0.}

\section{Alinhamento ascendente e descendente}

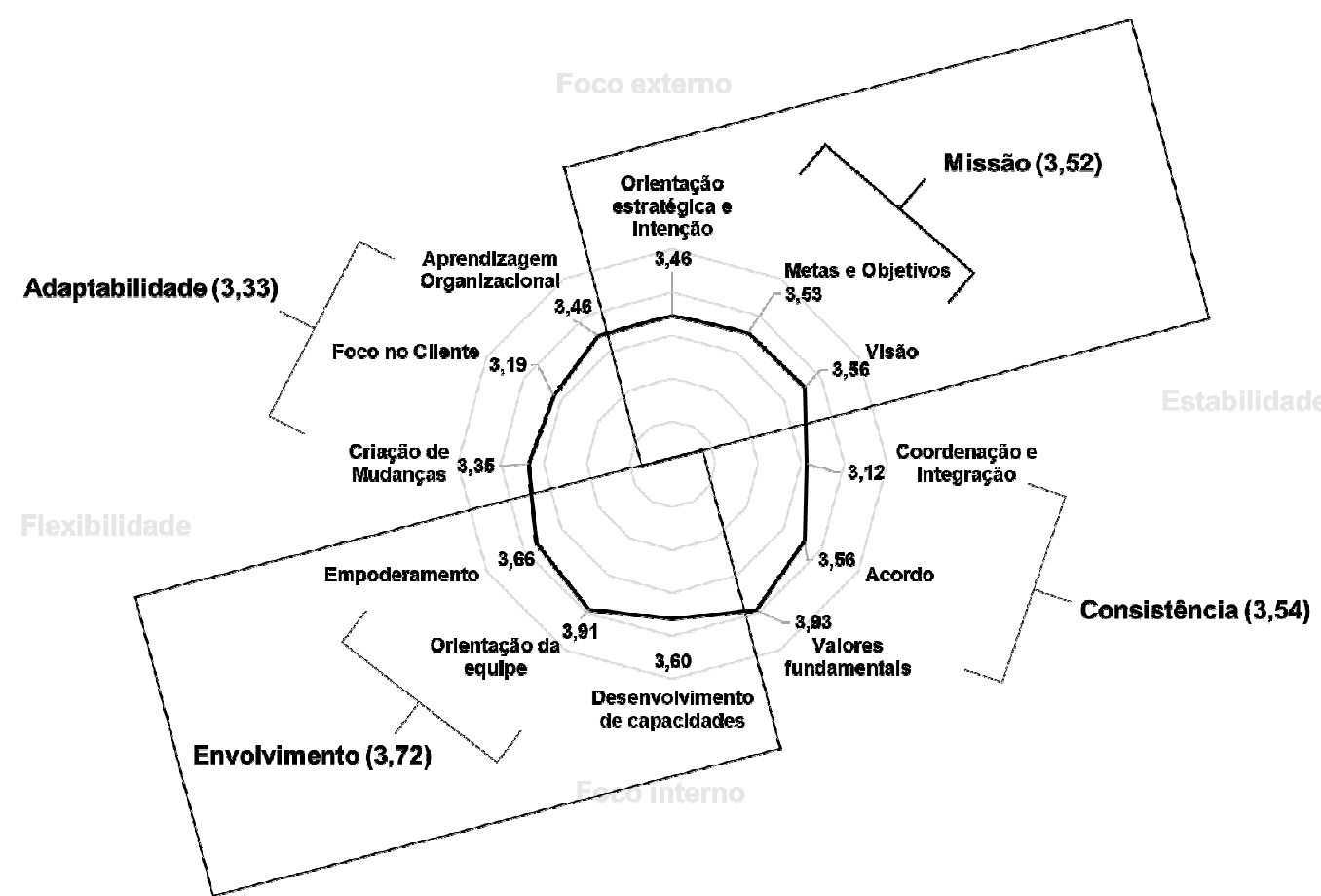

Figura 11 - Resultado Alinhamento ascendente e descendente

O resultado pode indicar um equilíbrio entre a missão (de cima para baixo) e o envolvimento dos funcionários (de baixo para cima). Esta organização entende que deve aprender a vincular o propósito e as estratégias da organização com o senso compartilhado de responsabilidade, propriedade e comprometimento dos funcionários. O equilíbrio entre esses traços, pode indicar uma comunicação bidirecional eficaz e uma força de trabalho comprometida e focada. 


\subsubsection{1.}

\section{Cadeia de valor do cliente}

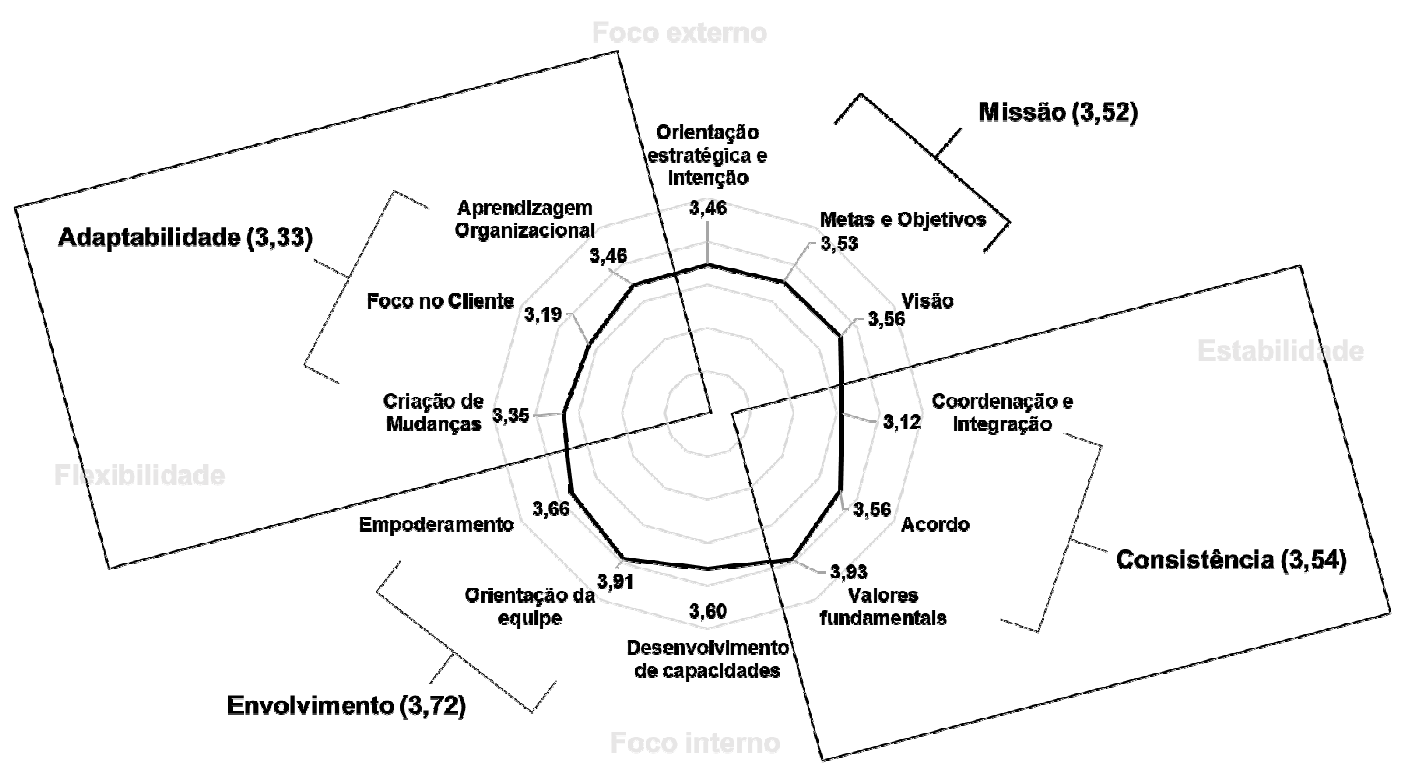

Figura 12 - Resultado Cadeia de valor do cliente

A Cadeia de valor do cliente (adaptabilidade mais consistência) é representada pela tensão criada entre adaptabilidade, que se preocupa amplamente com o mercado e a consistência, que analisa os valores, sistemas e processos internos. O resultado pode indicar que esta organização é capaz de se adaptar e responder ao mercado e desenvolver sistemas e processos que the permitam produzir produtos e serviços de qualidade.

Kotrba et al. (2012) analisaram a ideia de que os efeitos da consistência cultural no desempenho corporativo podem variar de acordo com os níveis de outros traços culturais e os resultados mostraram que empresas que são ao mesmo tempo consistentes e adaptáveis, por exemplo, apresentam alto desempenho.

\subsection{Apresentação e análise do desempenho financeiro}

Esta seção apresentará e analisará o desempenho financeiro da empresa nos últimos 5 anos (2012 a 2016). Existem outros indicadores de desempenho utilizados para acompanhamento do resultado, mas para analisarmos a relação entre cultura e desempenho, como proposto no modelo de Denison (The Denison Organizational Culture Model - DOCS - DENISON, 1990), analisaremos indicadores previstos em uma análise financeira, mais especificamente nos índices de rentabilidade - ROS, ROA e ROE. 
Antes de iniciarmos a análise dos indicadores, faremos uma breve apresentação e análise dos resultados entre os anos de 2012 e 2016 do ativo total, patrimônio líquido, lucro líquido e faturamento e do CAGR (Compound Annual Growth Rate), que mede a taxa composta média anual de crescimento de retorno de um investimento durante um determinado período de anos; portanto representa o ganho anual uniformizado obtido com um investimento durante um determinado horizonte temporal.

\subsection{1.}

\section{Ativo total}

\section{ATIVO TOTAL}

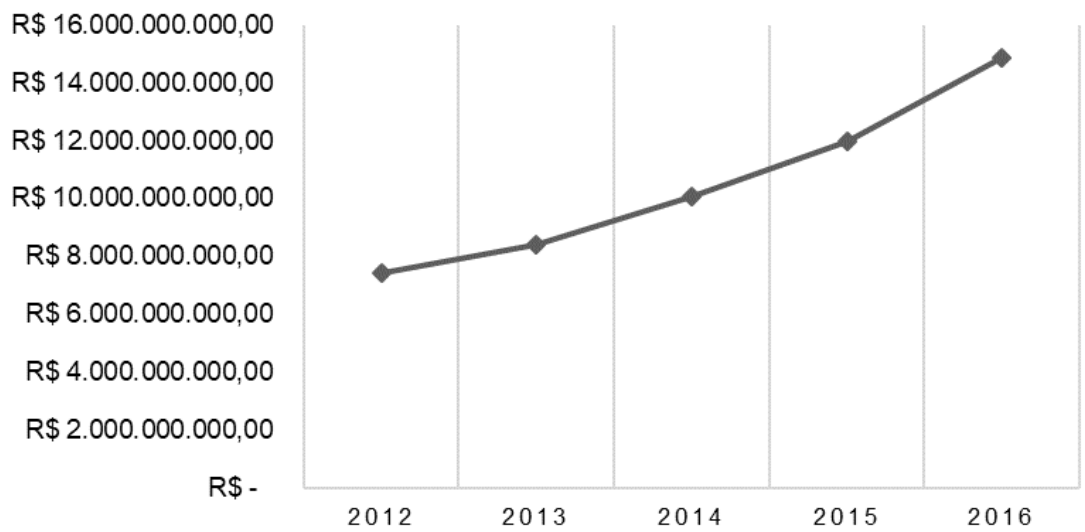

Figura 13 - Resultado Ativo Total

O ativo total representa todos os bens e direitos de propriedade da empresa, avaliáveis em dinheiro, que representam benefícios presentes ou futuros para a empresa. $O$ ativo total da empresa vem crescendo a uma taxa composta média anual de 18,97\%. 


\subsection{2.}

\section{Patrimônio líquido}

\section{PATRIMÔNIO LÍQUIDO}

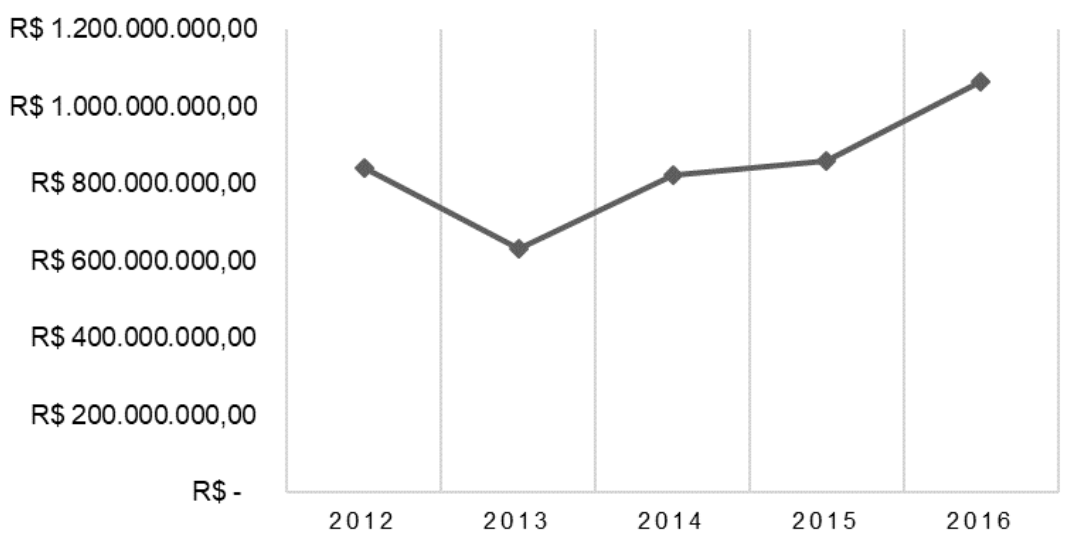

Figura 14 - Resultado Patrimônio Liquido

O patrimônio líquido representa os investimentos dos proprietários (Capital) além das Reservas (destino específico para o lucro não distribuído) e outros itens. O patrimônio líquido da empresa vem crescendo a uma taxa composta média anual de $6,09 \%$.

\subsection{3.}

\section{Lucro líquido}

\section{LUCRO LÍQUIDO}

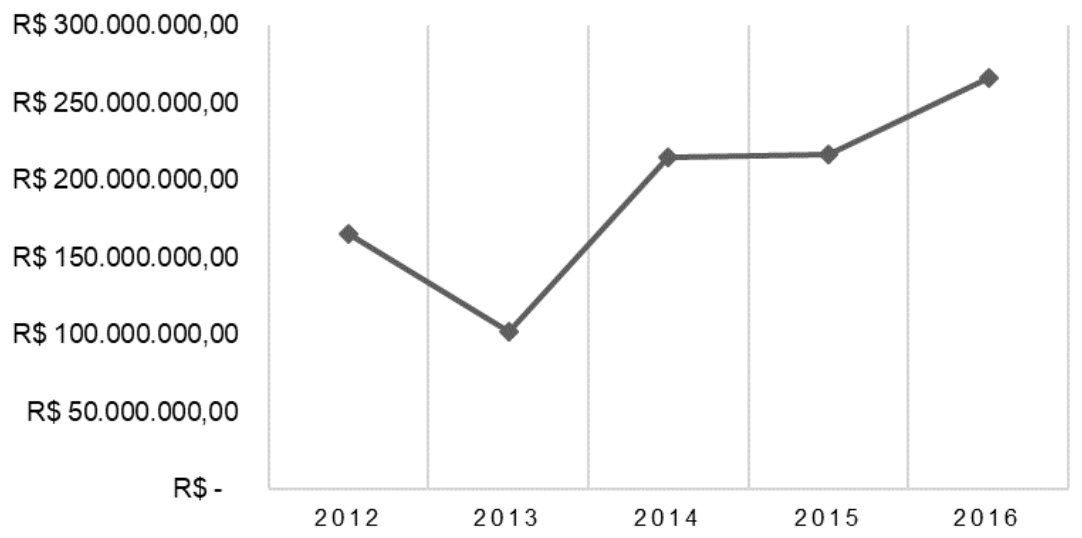

Figura 15 - Resultado Lucro Liquido

O lucro líquido é a sobra pertencente aos proprietários (ou à entidade). Após a apuração do Lucro depois do Imposto de Renda, faz-se a dedução das participações e, previstas nos estatutos: de debentures, de empregados, de administradores e das contribuições para instituições ou fundos de assistência ou previdências de empregados. O lucro líquido da empresa vem crescendo a uma taxa composta média anual de 12,65\%. 
4.3.4.

\section{Faturamento}

\section{FATURAMENTO}

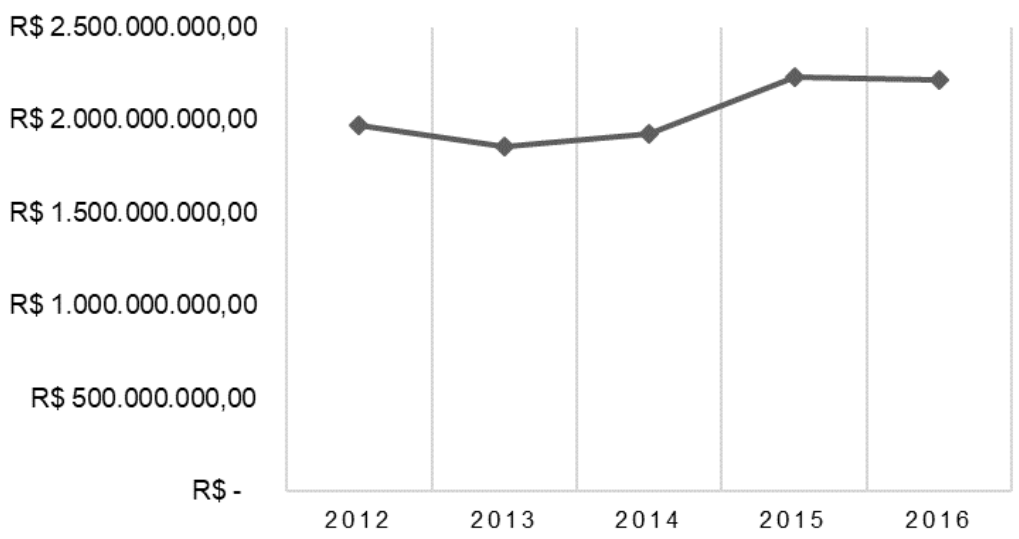

Figura 16 - Resultado Faturamento

O faturamento da empresa pesquisada é calculado com a seguinte fórmula: prêmios emitidos + contribuições para cobertura de riscos + resultado com resseguro + rendas de contribuições e prêmios - planos de aposentadoria + rendas com taxa de gestão e outras taxas. O faturamento da empresa vem crescendo a uma taxa composta média anual de $2,94 \%$.

\subsection{5.}

Return on Sales (ROS)

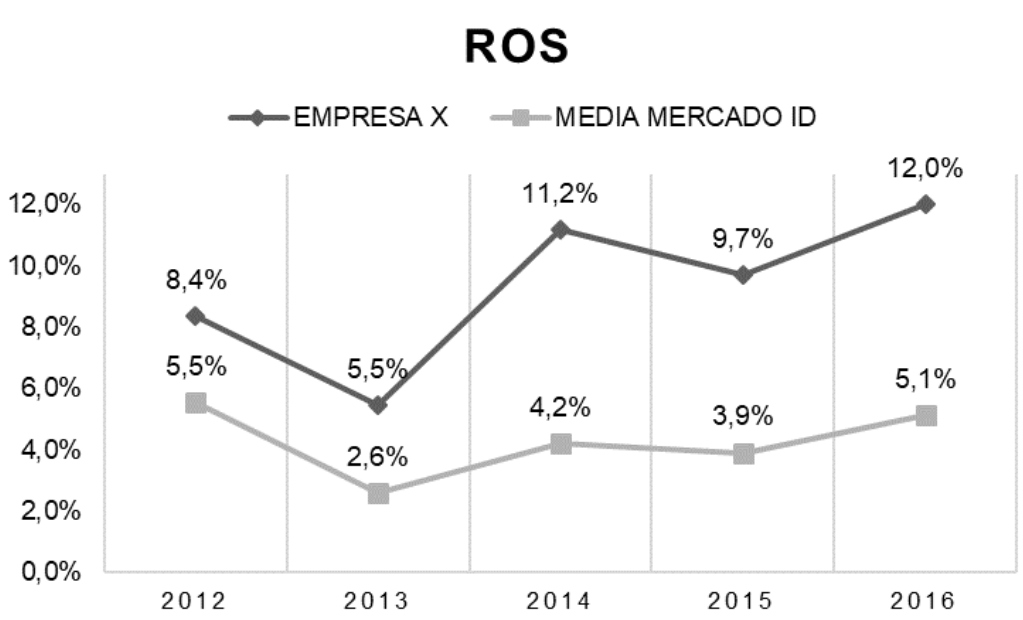

Figura 17: Resultado Return on Sales (ROS)

O Return on Sales (ROS) trata da relação entre lucro líquido e faturamento (já detalhados anteriormente). 
Analisando o gráfico acima, observa-se que o ROS da empresa pesquisada está acima da média de mercado das principais independentes. A queda observada em 2013 está em linha com a média de mercado e nova queda em 2015 é consequência de um crescimento proporcionalmente maior do faturamento em comparação a 2014 ( $R \$ 1,9$ bi para $R \$ 2,2$ bi), frente a um aumento mais modesto do lucro líquido entre 2014 e 2015 (R\$ 215 mil para $R \$$ $216,5 \mathrm{mil})$.

Conforme gráficos abaixo (DENISON, 1984), as organizações com culturas mais fortes (como medidas no exemplo abaixo por envolvimento) tem melhor Return on Sales (ROS). O que é muito marcante é a tendência ao longo do tempo. Na primeira, culturas mais fortes apenas melhoram um pouco, mas os efeitos de culturas mais fortes são cumulativos. Ao final de 5 anos, o efeito é dramático.

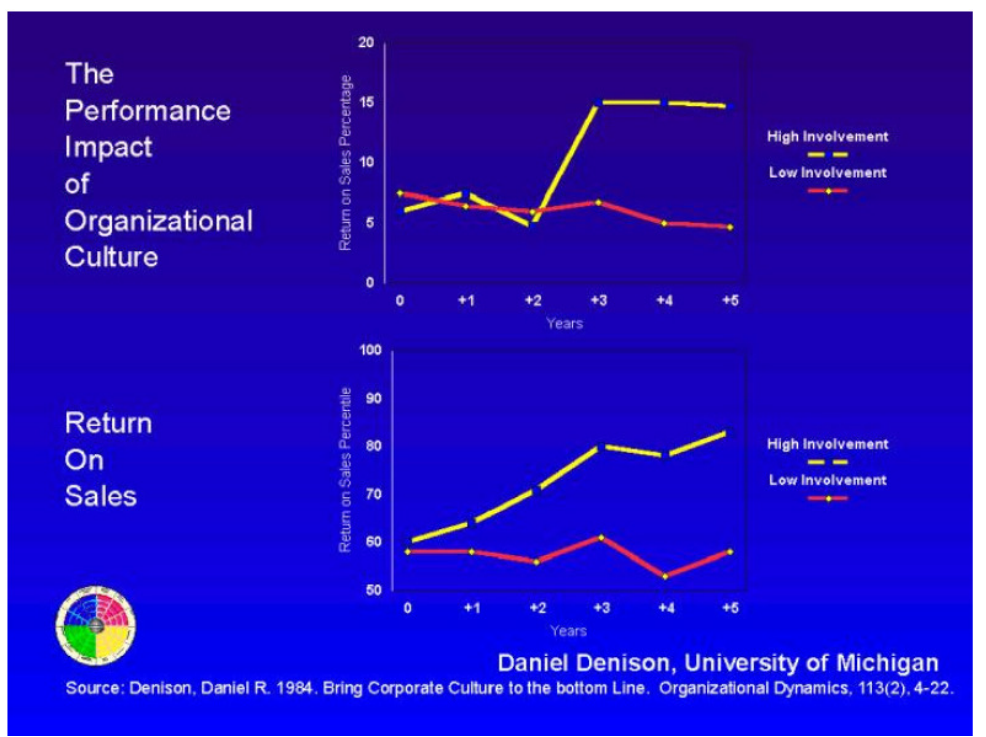

Figura 18 - Resultado Cultura e Return on Sales (ROS)

Fonte: DENISON, D. and NEALE, W. S. Denison organizational culture survey: facilitator guide 


\subsection{6.}

\section{Return on Assets (ROA)}

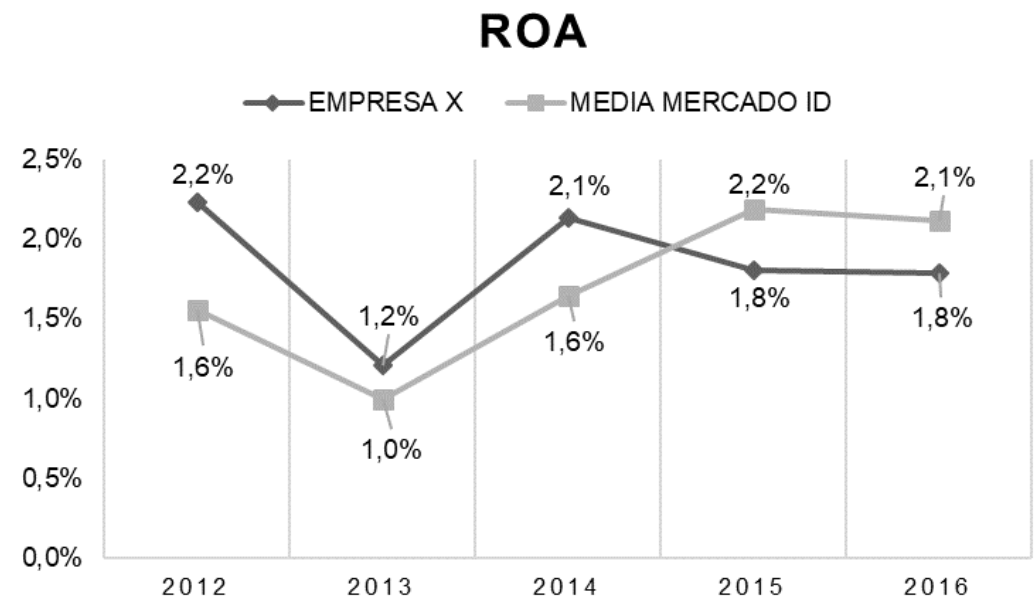

Figura 19 - Resultado Return on Assets (ROA)

O Return on total Assets ( $R O A)$ trata da relação entre o lucro líquido e ativo total e mede o retorno sobre ativo total após juros e impostos (já detalhados anteriormente).

Analisando o gráfico acima, observa-se que o ROA da empresa pesquisada sofre oscilações ao longo dos anos. Novamente se observa uma queda em 2013, em linha com a média de mercado e nova queda em 2015 é consequência de um crescimento proporcionalmente maior do ativo total em comparação a $2014(\mathrm{R} \$ 10$ bi para $R \$ 12$ bi), frente a um aumento modesto do lucro líquido entre 2014 e 2015 ( $R \$ 215$ mil para $R \$ 216,5$ mil).

\subsection{7.}

\section{Retorno sobre Patrimônio Líquido (ROE)}

\section{ROE}

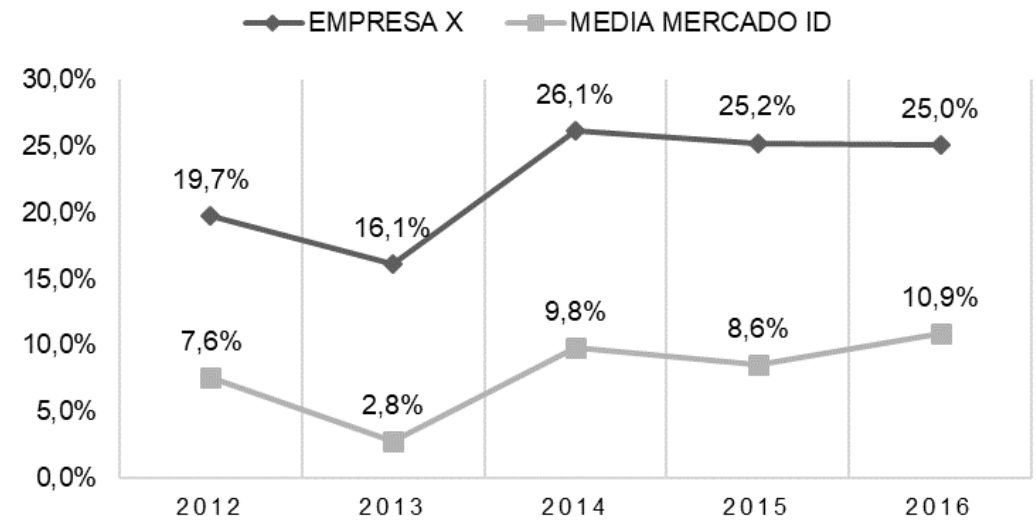

Figura 20 - Resultado Retorno sobre Patrimônio Líquido 
O Retorno sobre Patrimônio Líquido (ROE) trata da relação entre o lucro líquido e o patrimônio líquido (já detalhados anteriormente). Neste estudo, por ser um indicador mais comum no mercado de seguros, ele substitui o ROI indicado nos estudos de Denison.

Analisando o gráfico acima, observa-se que o ROE da empresa pesquisada está acima da média de mercado das principais independentes.

Conforme gráfico abaixo (DENISON, 1984), as organizações com culturas mais fortes (como medidas no exemplo abaixo por envolvimento) tem melhor Return on Investment (ROI).

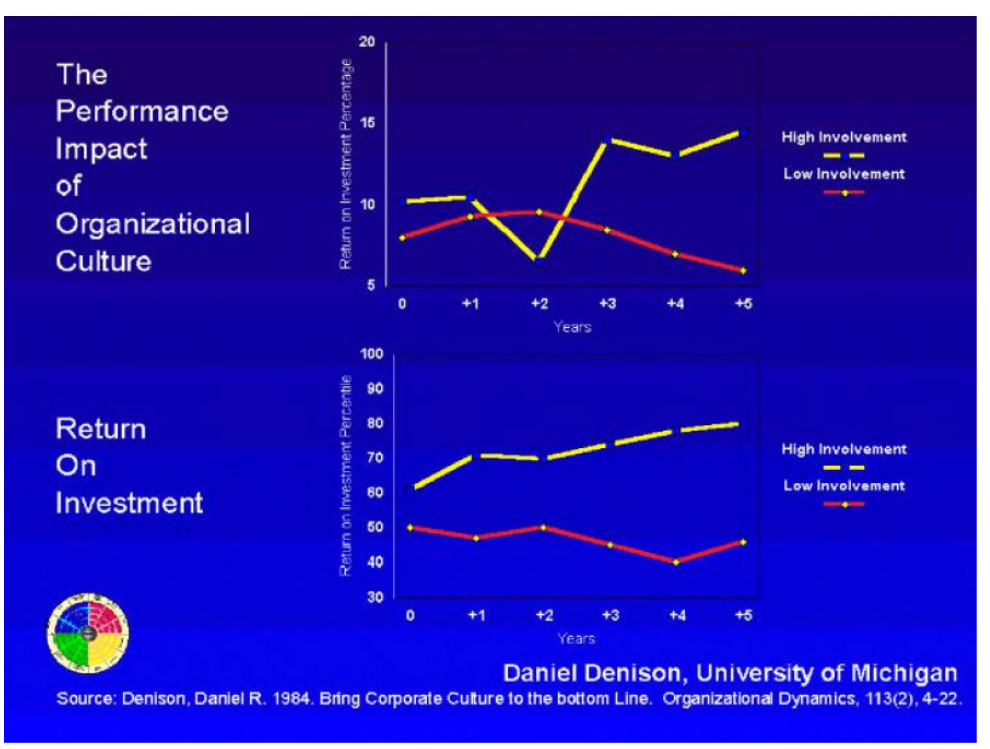

Figura 21 - Resultado Cultura e Return on Investment

Fonte: DENISON, D. and NEALE, W. S. Denison organizational culture survey: facilitator guide 


\section{5 \\ Conclusão}

Este trabalho teve como objetivo analisar a relação da Cultura e o Desempenho Organizacional. Tal questão se mostra relevante na medida que a cultura organizacional é um ingrediente essencial do desempenho organizacional e uma fonte de vantagem competitiva sustentável (CHILDRESS, 2013; KOHTAMAKI, THORGREN e WINCENT, 2016) e agir sem conhecer as forças culturais pode ter resultados imprevisíveis e indesejáveis, visto que ela interage com recursos humanos, estrutura organizacional e incluirá crenças, atitudes, pressupostos e expectativas comuns direcionando comportamentos na ausência de uma lei ou instruções claras (AHMADY et al., 2016).

Dentre as principais análises deste estudo, a primeira delas advém da relação entre o resultado das dimensões culturais e os apresentados no desempenho financeiro. Observou-se que as médias das dimensões culturais Missão $(3,52)$, Consistência $(3,54)$, Envolvimento $(3,72)$ e Adaptabilidade $(3,33)$ estão com resultados bem distribuídos e próximos (desvio padrão de 0,16 ) e que os resultados dos indicadores de desempenho financeiro avaliados na empresa pesquisada apresentam resultado acima da média de mercado nos últimos 5 anos. Este resultado está em linha com o apresentado por Denison (The Denison Organizational Culture Model - DOCS - DENISON, 1990), que salienta que a cultura de uma organização efetiva, ou seja, com bom desempenho, deve refletir todas as dimensões previstas no modelo e também está em linha com a pesquisa realizada por Hause (2000), onde os resultados mostraram que tanto o nível quanto as medidas de acordo da força da cultura organizacional são preditivas da eficácia organizacional.

A próxima análise diz respeito ao resultado da dimensão Missão e o desempenho. Ser capaz de internalizar e se identificar com a missão de uma organização contribui para o compromisso a curto e longo prazo com a organização. O estudo de Yilmaz e Ergun (2008) indicou que o traço missão era o mais importante em termos de promover o desempenho global da empresa, assim como o crescimento das vendas, o crescimento da participação de mercado e o retorno sobre ativos, assim como Mario Ernesto (2010) concluiu 
que somente o traço missão evidencia relações significativas com algumas medidas de desempenho.

Outra análise diz respeito aos resultados das dimensões Consistência e Adaptabilidade e o desempenho. Estes resultados podem indicar que esta organização é capaz de se adaptar e responder ao mercado e desenvolver sistemas e processos que the permitam produzir produtos e serviços de qualidade e que impulsionem seu desempenho. Os resultados encontrados também são sustentados pela pesquisa realizada por Kotrba et al. (2012) que concluíram que empresas que são ao mesmo tempo consistentes e adaptáveis apresentam alto desempenho.

Uma outra análise diz respeito a relação entre as dimensões Consistência e Missão e o desempenho. Os resultados destas dimensões sugerem que houve uma influência destes traços culturais nas medidas de desempenho financeiro como retorno sobre ativos (ROA), retorno sobre Patrimônio Líquido (ROE) e retorno das vendas (ROS). O estudo realizado por Tedla (2016) em um grupo corporativo na Etiópia confirmou que missão e visão bem definidas, alinhamento dos principais valores corporativos, liderança focada nos funcionários e consistência são as melhores estratégias utilizadas para estabelecer uma cultura organizacional eficaz e melhorar o desempenho no grupo estudado.

$\mathrm{E}$ para concluir, cabe também analisar o resultado das dimensões Consistência e Envolvimento e o resultado do ROE. Segundo o modelo, o resultado destas dimensões afeta a qualidade, a satisfação dos funcionários e o retorno do investimento. Ou seja, os resultados encontrados podem indicar níveis mais altos de qualidade, menos defeitos e menos retrabalho, boa utilização de recursos e níveis mais altos de satisfação dos funcionários.

\section{1.}

\section{Sugestões e recomendações para novas pesquisas}

Como desdobramentos futuros, podemos sugerir a ampliação desta pesquisa pela análise histórica com séries temporais que permitam um corte longitudinal do estudo de caso.

Também podemos recomendar, pela realização de múltiplos estudos de casos, a ampliação da análise das vantagens competitivas da cultura organizacional na comparação entre organizações do mesmo setor. 
Além disso, o aprofundamento da análise qualitativa, utilizando referencial antropológico de manifestações culturais a partir da compreensão dos ritos, mitos, historias, artefatos visíveis, lemas, heróis, etc., pode ampliar a análise da relação cultura e desempenho.

A extensão desta linha de pesquisa também é recomendada pela comparação da análise baseada no modelo de Cultura Organizacional de Denison (The Denison Organizational Culture Model - DOCS - DENISON, 1990)) com outras tipologias culturais como por exemplo, a de Handy (1976), que considera como os canais de poder são refletidos em determinadas estruturas e sistemas, a de Sethia e Glinow (1985) que propõe um modelo que relaciona a orientação para pessoas e para resultados, ou a tipologia de Deal e Kennedy (1982) que avalia a relação risco do investimento e a velocidade do feedback do mercado no qual a organização atua.

E para se ter representatividade que nos permitam generalizações do que foi apresentado neste estudo, se sugere a expansão amostral para uma possível análise quantitativa dos resultados. 


\section{Referências bibliográficas}

AHMADY, G. A.; NIKOORAVESH, A.; MEHRPOUR, M. Effect of Organizational Culture on knowledge Management Based on Denison Model. Procedia - Social and Behavioral Sciences. p. 230, 3rd International Conference on New Challenges in Management and Business: Organization and Leadership, 2 May 2016, Dubai, UAE, 387-395, ISSN: 1877-0428. Sept. 12, 2016.

AMOS, E. A.; WEATHINGTON, B. L. An analysis of the relation between employee--organization value congruence and employee attitudes. The Journal of Psychology. ISSN: 0022-3980. v. 6, p. 615, 2008.

ASHKANASY, N. M.; WILDEROM, C. P.; PETERSON, M. F. (Eds.). Handbook of organizational culture and climate. Sage. 2000.

BARNEY, J. B. Gaining and Sustaining Competitive Advantage. 2a ed. New Jersey. Prentice Hall. 2002.

Organizational culture: Can It Be a Source of Sustained Competitive Advantage? Academy of Management Review. v. 11, p. 656-665. 1986.

BARROS, B. T.; PRATES, M. A. S. O estilo brasileiro de administrar. São Paulo: Atlas, 1996.

BECKER, G. Human capital: A theoretical and empirical analysis with special reference to education. New York, NY: Columbia University Press. 1964.

BLOCK, P. The empowered manager: Positive political skills at work. San Francisco, CA: Jossey-Bass. 1991.

BRIGHAM, E. F.; EHRHARDT, M. C. Administração financeira: teoria e prática. São Paulo: Cengage Learning, trad 13ed. 2015. ISBN 13: 978-85-2211099-5.

CABLE D. M.; JUDGE, T. A. Person-organization Fit, Job Choice Decisions, and Organizational Entry. Organizational Behavior and Human Decision Processes, v. 67, n. 3, 1996.

CAMERON K. S. Domains of organizational effectiveness in colleges and universities. Academy of Management Journal. v. 24(1), p. 25-47. 1981. ; QUINN, R. E. Diagnosing and changing organizational culture: based on the competing values framework. Addison-Wesley, 1999. .; $\quad$.; DEGRAFF, J.; THAKOR, A. V. Competing Values Leadership: Creating Value in Organizations. Cheltenham: Edward Elgar, 2006. 
CHATMAN, J. A. Matching People and Organizations: selection and socialization in public accounting firms. Administrative Science Quarterly, v. 36, 1991. .; JEHN, K. Assessing the Relationship between Industry Characteristics and Organizational Culture: How Different Can You Be? Academy of Management Journal, v. 37, p. 522-553, 1994.

CHELLADURAI, P.; HAGGERTY, T. Measures of organizational effectiveness of Canadian national sport organizations. Canadian Journal of Sport Sciences. v. 16(2), p. 126-133. 1991.

CHILDRESS, J. R. Leverage: The CEO's guide to corporate culture [Kindle Edition version]. Disponível em: <http://www.amazon.com>. 2013.

COOKE, R. A.; ROUSSEAU, D. M. Behavioral norms and expectations: A quantitative approach to the assessment of organizational culture. Group and Organizational Studies, v. 13(3), p. 245-273. 1988.

COPELAND, T. E.; WESTON, J. F. Financial theory and corporate policy. Reading, MA: Addison-Wesley. 1979.

CRESWELL, J. W. Projeto de Pesquisa: métodos qualitativo, quantitativo e misto. Porto Alegre: Artmed, 3ed. 2010.

CROZATTI, J. Cultura organizacional e modelo de gestão: conceitos, interações e implicações para a eficácia. Caderno de estudos. São Paulo, v. 10, n. 18, maio/ago. 1998.

CUNHA, R.; COOPER, C. Does privatization affect corporate culture and employee wellbeing? Journal of Managerial Psychology, v. 17(1-2), p. 21-49. 2002.

DANDRIDGE, T.; MITROFF, I.; JOYCE, W. Organizational Symbolism: A topic to expand organizational analysis. Academy of Management Review, 5, 77-82. (1980).

DAVENPORT, T. Process innovation: Re-engineering work through information technology. Boston, MA: Harvard Business School Press. 1993.

DEAL, T. E.; KENNEDY, A. A. Corporate cultures: The rites and rituals of corporate life. Massachusetts: Addison-Wesley, 1982.

DENISON, D. R. Bringing Corporate Culture to the Bottom Line.

Organizational Dynamics, v. 13, n. 2, p. 4-22. 1984. Corporate culture and organizational effectiveness. New York: John Wiley and Sons. 1990.

Organizational culture: can it be a key lever for driving organizational change? Lausanne: International Institute for Management Development. 2000.

What is the Difference between Organizational Culture and

Organizational Climate? A Native's Point of View on a Decade of Paradigm Wars. The Academy of Management Review. ISSN: 03637425. v. 3, p. 619, 1996.

; JANOVICS, J.; YOUNG, J.; CHO, H. J. Diagnosing organizational cultures: Validating a model and method. Working Paper, International Institute for Management Development, Lausanne, Switzerland. (2006). 
.; MISHRA, A. Toward a theory of organizational culture and

effectiveness. Organizational Science, v. 6(2), p. 204-223. 1995.

; NEALE, W. S. Denison organizational culture survey: facilitator guide. Ann Arbor (MI): Aviat. 1996.

.; SPREITZER, G. M. Organizational culture and organizational

development: A competing values approach. In: research in organizational change and development. Greenwich, CT: JAI Press. v. 5, p. 1-21. 1991.

.; HAALAND, S.; GOELZER, P. Corporate culture and organizational effectiveness: is there a similar pattern around the word? Advances in Global Leadership, v. 3, p. 2005-2227. 2003.

.; _ _ _ NEALE, W. S. Linking Corporate Culture and Customer

Satisfaction: Two Empirical Studies. Presented at the 17th Annual Society of Industrial/Organizational Psychologists Conference: Toronto, ON. 2002.

; HOOIJBERG, R.; LANE, N.; LIEF, C. A força da cultura organizacional nas empresas globais: como conduzir mudanças de impacto e alinhar estratégia e cultura. $1^{\underline{a}}$ ed. Rio de Janeiro: Elsevier, ISBN13: 978-8535264128. 2013.

DESHPANDE, R.; WEBSTER, F. E. Organizational culture and marketing: defining the research. Journal of Marketing, v. 53, n. 1, p. 3-15, 1989.

DISKIENĖ, D.; GOŠTAUTAS, V.; A fit between individual and organizational values and its implications for employees' job satisfaction and performance. Ekonomika (Economics), v. 92, n. 2, 2013.

EUMEDNET Universidad de Málaga, España; Cota, B. y Calvillo, F. Capitulo 2: La cultura organizacional como factor condicionante de la productividad: El caso de una empresa de la industria del plástico en Jalisco, 36-65. 2008.

FEY, C.; DENISON, D. Organizational culture and effectiveness: can American theory be applied in Russia? Organization Science, v. 14(6), p. 686706. 2003.

FLAMHOLTZ, E.; Randle, Y. Corporate culture, business models, competitive advantage, strategic assets, and the bottom line. Journal of Human Resource Costing \& Accounting, v. 16, p. 76-94. doi:10.1108/14013381211284227. 2012.

FREITAS, M. E. Cultura organizacional: formação, tipologias e impactos. São Paulo: Makron, 1991.

GIL, A. C. Como elaborar projetos de pesquisa. São Paulo: Ed. Atlas, 1991.

GLASER, B. J. Organizational Culture and Financial Performance and the Moderating Effect of Organizational Age. Dissertação. 2014.

GOFFEE, R.; JONES, G. Organizational culture: a sociological perspective. In: COOPER, C. L.; CARTWRIGHT, S.; EARLEY, P. C. (Eds.). The international handbook of organizational culture and climate. Chichester Wiley. 2001.

GORDON, G. G.; DITOMASO, N. Predicting corporate performance from organizational culture. Journal of Management Studies, v. 29(6), p. 783798. 1992. 
GREGORY, B. T.; HARRIS, S. G.; ARMENAKIS, A. A.; SHOOK, C. L. Organizational culture and effectiveness: A study of values, attitudes, and organizational outcomes. Journal of Business Research. v. 62(7), p. 673-679. 2009.

GROYSBERG, B.; LEE, J.; PRICE, J.; CHENG, Y. J. The Leader's Guide to Corporate Culture - MAGAZINE ARTICLE; Disponível em: $<$ https://hbr.org/2018/01/the-culture-factor\#context-conditions-andculture?autocomplete=true $>$.

HAMEL, G.; PRAHALAD, C. K. Competing for the future. Boston, MA: Harvard Business School Press. 1994.

HANDY, C. Como Compreender as Organizações. Ed. Zahar, 1976.

HARRISON, R. Understanding your organization's charter. Harvard Business Review, May-June, p. 119-128. 1972.

HARTNELL, C.; OU, A.; KINICKI, A. Organizational culture and organizational effectiveness: A meta-analytic investigation of the competing values framework's theoretical suppositions. Journal of Applied Psychology, doi:10.1037/a0021987. v. 96, p. 677-694. 2011.

HAUSE, O. R. Relationships between organizational culture strength and organizational effectiveness in an electrical utility company (Order No. 9994100). Available from ProQuest Dissertations \& Theses Global. (304601673). Retrieved from: <http://139.82.115.33/docview/304601673?accountid=26649>. 2000.

HERIS, M. S. Effects of organizational culture on organizational effectiveness in Islamic Azad Universities of Northwest of Iran. Indian Journal of Fundamental and Applied Life Sciences. ISSN: 2231- 6345 (Online) An Open Access, Online International Journal Available at: <www.cibtech.org/sp.ed/jls/2014/03/jls.htm>. Heris. v. 4(S3), p. 250-256. 2014.

HIRSHLEIFER, J. Price theory and its applications. ( $2^{\text {nd }}$ ed.). Englewood Cliffs, NJ: Prentice-Hall. 1980

IPLIK, F. N.; KILIC, K. C.; YALCIN, A.; The simultaneous effects of personorganization and person-job fit on Turkish hotel managers, International Journal of Contemporary Hospitality Management, v. 23, n. 5, p. 644-661, 2011.

JEFFREY B.; ARTHUR, A. Effects of Human Resource Systems on Manufacturing Performance and Turnover. The Academy of Management Journal. ISSN: 00014273. v. 3, p. 670, 1994.

KILMANN, R. H.; SAXTON, M. J.; SERPA, R. Five key issues in understanding and changing culture. In:

San Francisco: Jossey-Bass, 1985.

KING, M. Deep culture. Journal of Popular Culture, v. 45, p. 687-694. doi:10.1111/j.1540-5931.2012.00952.x. 2012.

KINICKI, A.; KREITNER, R. Organizational behavior: Key concepts, skills \& best practices. McGraw-Hill/Irwin. 2006. 
KOHTAMAKI, M.; THORGREN, S.; WINCENT, J. Organizational identity and behaviors in strategic networks. Journal of Business \& Industrial Marketing, doi:10.1108/JBIM-07-2014-0141. v. 31, p. 36-46. 2016.

KOTRBA, L. M. et al. Do consistent corporate cultures have better business performance? Exploring the interaction effects. HUMAN RELATIONS. 65, 2, 241262, ISSN: 00187267.

KOTTER, J.; HESKETT, J. Corporate Culture and Performance. New York: Free Press, 1992.

KWANTES, C. T.; BOGLARSKY, C. A. Perceptions of organizational culture, leadership effectiveness and personal effectiveness across six countries. Journal of International Management. v. 13(2), p. 204-230. 2007.

LACASSE, J. A. A Multimethod Organizational Culture Analysis of a State Correctional Institution Using a Modified Denison Organizational Culture Survey. A Dissertation Submitted to the Faculty of the School of Education of The University of St. Thomas St. Paul, Minnesota - May 2010

LAUVER, K. J.; KRISTOF-BROWN, A. Distinguishing between Employees' Perceptions of Person-job Fit and Person-Organization Fit. Journal of Vocational Behavior, v. 59, p. 454-470, 2001.

LAWLER, E. E. III. From the ground up: Six principles for building the new logic corporation. San Francisco, CA: Jossey-Bass. 1996.

LIKERT, R. New patterns of management. New York, NY: McGraw-Hill. 1961.

LOPEZ, T. B.; BABIN, B. J. Perceptions of ethical work climate and personorganization fit among retail employees in Japan and the US: A cross-cultural scale validation. Journal of Business Research, v. 62, p. 594-600, 2009.

LORSCH, J. W. Strategic myopia: culture as an invisible barrier to change. In: KILMANN, R. H.; SAXTON, M. J.; SERPA, R. and associates (Eds.), Gaining Control of the Corporate Culture, San Francisco: Jossey-Bass, p. 84-102. 1985.

MACINTOSH, E. W.; DOHERTY, A. The influence of organizational culture on job satisfaction and intention to leave. Sport Management Review. v. 13(2), p. 106-117. 2010.

MARIO ERNESTO, M. A. Relaciones entre cultura y desempeño organizacional en una muestra de empresas colombianas: reflexiones sobre la utilización del modelo de Denison / Relations between organizational culture and organizational performance in a sample of Colombian companies: reflections on using Denison's model / Relações entre cultura e desempenho organizacional em uma mostra de empresas colombianas: reflexões sobre a utilização do modelo de Denison. Cuadernos de Administración. Bogotá, ISSN: 0120-3592. v. 40, p. 163, 2010.

MARTIN, J.; SIEHL, C. Organizational culture and counterculture: An uneasy symbiosis. Organizational Dynamics, v. 12, p. 52-64. 1983. 
MCKELVEY, W. Organizational systematics: Taxonomy, evolution, classification. Los Angeles: University of California Press. 1982.

MICHAEL, A. E. Investigating relationships between person-environment fit, job Satisfaction and turnover intentions in Cyprus. Proceedings of the Northeast Business \& Economics Association, p. 125-129, 2009.

MINTZBERG, H. Crafting strategy. Harvard Business Review, 65, 66-75. 1987. The rise and fall of strategic planning: Reconciling for planning, plans, planners. New York, NY: Free Press. 1994.

MONAVARIAN, A.; BAKHTAE, A. Knowing organizational culture based on Denison model: organization of industrial management. 4th international conference of management. Tehran: research group of Ariya. Retrieved from: <http://www.civilica.com/Paper-IRIMC 14 -IRIMC 14 _ 131 .html>. 2006.

NADLER, D. Champions of change: How CEOs and their companies are mastering the skills of radical change. San Francisco, CA: Jossey-Bass. 1998.

OHMAE, K. The mind of the strategist: The art of Japanese business. New York, NY: McGraw- Hill. 1982.

O'REILLY, C. A. III.; CALDWELL, D.; CHATMAN, J.; DOERR, B. The promise and problems of organizational culture: CEO personality, culture, and firm performance. Group \& Organization Management, doi:10.1177/1059601114550713. v. 39, p. 595-625. 2014.

; CHATMAN, J.; CALDWELL, D. F. People and organizational culture: A profile comparison approach to assessing person organization fit. Academy of Management Journal, v. 34(3), p. 487-516. 1991.

ORTEGA-PARRA, A.; SASTRE-CASTILLO, M. Impact of perceived corporate culture on organizational commitment. Management Decision, doi:10.1108/MD08-2012-0599. v. 51, p. 1071-1083. (2013).

OUCHI, W. G. Theory Z. New York: Avon Books. 1981.

PASCALE, R. T.; ATHOS, A. G., The art of Japanese management, Ed. Simon and Schuster, New York, 1981.

PETERS, T. J.; WATERMAN Jr, R. H. In Search of Excellence, Harper \& Row, New York, 1982.

PETTIGREW, A. On studying organizational cultures. Administrative Science Quarterly, v. 24, p. 570-581. 1979.

PRITCHARD, R. D.; KARASICK, B. W. The effects of organizational climate on managerial job performance and job satisfaction. Organizational Behavior and Human Performance, v. 9, p. 126-146. 1973.

QUINN, R. E.; ROHRBAUGH, J. A spatial model of effectiveness criteria: Towards a competing values approach to organizational analysis. Management Science, v. 29, p. 363-377. 1983. 
REICHERS, A. E.; SCHNEIDER, B. Climate and culture: An evolution of constructs. In: SCHNEIDER, B. (Ed.), Organizational Climate and Culture. San Francisco: Josey-Bass Inc. p. 5-39. 1990.

SAFFOLD, G. Culture traits, strength, and organizational performance: Moving beyond "strong" culture. Academy of Management Review, v. 13(4), p. 546558. 1988.

SANJAR, S.; ALI, N. Investigating characteristics of organizational culture. Management Science Letters. 11, 2427, 2014. ISSN: 1923-2934. v. 4, Iss 11, p. 2427-2432. 2014.

SCHEIN, E. H. Organizational Culture and Leadership. San Francisco. JosseyBass. 1985.

1990. Organizational Culture. American Psychologist, v. 45, p. 109-119.

Organizational Culture and Leadership. 3.ed. San Francisco: Jossey-Bass, 2004.

SCHNEIDER, B.; EHRHART, M. G.; MACEY, W. H. Organizational Climate and Culture. Annual Review of Psychology. ISSN: 00664308. v. 64, n. 1, p. 361388, Feb. 2013.

SCHNEIDER, W. Productivity improvement through cultural focus. Consulting Psychology Journal. v. 47, p. 3-27. 1995.

SCHWARTZ, H.; DAVIS, S. Matching Corporate Culture and Business Strategy. Organizational dynamics, p. 30-48. summer, 1981.

SCOTT, W. R. Effectiveness of organizational effectiveness studies. In: New Perspectives on Organizational Effectiveness, edited by GOODMAN, P. S.; PENNINGS, J. M. San Francisco: Jossey-Bass 63-95. 1977.

SENGE, $P$. The fifth discipline: The art and practice of the learning organization. New York, NY: Doubleday/Currency. 1990.

SETHIA, N.; VON GLINOW, M. A. Arriving at four Cultures by Managing the Reward System. In: KILMANN, et al. Gaining Control of the Corporate Culture, San Francisco: Josse-Bass, 1985.

SHARMA, G.; GOOD, D. The work of middle managers: Sense making and sense giving for creating positive social change. The Journal of Applied Behavioral Science, doi:10.1177/0021886312471375. v. 49, p. 95-122. 2013.

SHERIDAN, J. E. Organizational culture and employee retention. Academy of Management Journal, v. 35, p. 1036-1056. 1992.

SIMONEAUX, S.; STROUD, C. A strong corporate culture is key to success. Journal of Pension Benefits, Retrieved from:

<http://www.aspenpublishers.com>. v. 22(1), p. 51-53. 2014.

SMIRCICH, L. Concepts of culture and organizational. Administrative Science Quarterly, v. 28, n. 3, p. 339-358, 1983. 
SNELL, S.; YOUNDT, M. A., Human resource management and firm performance: Testing a contingency model of executive controls. Journal of Management, v. 21, p. 711-737. 1995.

SORIA, R. Emprendurismo, cultura, clima y comunicación organizacional y su aplicación a la pequeña y mediana empresa en la Zona Metropolitana de Guadalajara, México. Red Académica Iberoamericana Local - Global, Grupo EUMEDNET Universidad de Málaga, España; Cota, B. y Calvillo, F. Capitulo 2: La cultura organizacional como factor condicionante de la productividad: El caso de una empresa de la industria del plástico en Jalisco, 36-65. 2008.

SPREITZER, G. Psychological empowerment in the workplace: Dimensions, measurement, and validation. Academy of Management Journal, v. 38, p. 1442-1465. 1995.

STALK, G. Competing against time: How time-based competition is reshaping global markets. New York, NY: Free Press. 1988.

TEDLA, T. B. The Impact of Organizational Culture on Corporate Performance. 2016.

TOMEI, P. A. Cultura e Mudança Organizacional (org.), Editora PUC-Rio, Rio Janeiro, 2008.

O Que é a Cultura Organizacional? Editora Brasiliense, 2011

TURÁKOVÁ, A.; REČIČÁR, J. The corporate adaptability by DoCS Model as an element of corporate culture in relation to knowledge management. Proceedings of the Multidisciplinary Academic Conference. 1-7, Dec. 2013.

VERTEL, A. C. et al. Artículo: Cultura organizacional: evolución en la medición.: Organizational culture: developments in measuring (English). Estudios Gerenciales. ISSN: 0123-5923. v. 29, p. 350-355, July 1, 2013.

WILKINS, A. The culture audit: a tool for understanding organizations. Organizational dynamics, v. 12, p. 24-38. 1983.

YILMAZ, C.; ERGUN, E. Organizational culture and firm effectiveness: An examination of relative effects of culture traits and the balanced culture hypothesis in an emerging economy. Journal of World Business. ISSN: 10909516. v. 43, p. 290-306, jan. 1, 2008.

YIN, R. K. Estudo de caso - Planejamento e Métodos. 2 $2^{\mathrm{a}}$ ed. Porto Alegre: Bookman, 2001.

Bookman, 2005.

Estudo de caso - planejamento e métodos. $3^{\underline{a}}$ ed. Porto Alegre:

YIRDAW, A. The role of governance in quality of education in private higher education institutions: Ethiopia as a case study (Doctoral dissertation). Available from ProQuest Dissertations and Theses database. (UMI No. 3646173). 2014.

Sites pesquisados:

http://www2.susep.gov.br/menuestatistica/SES/principal.asp 


\section{Anexo 1}

Questionário do modelo de Cultura Organizacional de Denison - DOCS

O questionário sobre Cultura Organizacional de Daniel R. Denison foi concebido para mensurar crenças, valores e pressupostos subjacentes dos membros de uma organização e as práticas e comportamentos que os exemplificam e os reforçam.

E para respondê-lo, você deverá levar em consideração como sua organização é atualmente.

Suas respostas são confidenciais! O preenchimento completo levará alguns minutos.

Opções de resposta:

( ) discordo totalmente ( ) discordo ( ) neutro ( ) concordo ( ) concordo totalmente

\section{Afirmativas:}

Nesta organização...

1. A maioria dos funcionários está altamente envolvida em seu trabalho

2. As decisões são frequentemente tomadas em posições onde as melhores informações estão disponíveis

3. As informações são compartilhadas amplamente de maneira que todos possam ter acesso quando necessário

4. Cada pessoa acredita que pode exercer um impacto positivo

5. O planejamento do negócio é desenvolvido continuamente e de alguma maneira envolve a todos no processo

6. A cooperação entre diferentes partes da organização e incentivada

7. As pessoas trabalham como membros de uma equipe

8. O trabalho em equipe é usado para que uma tarefa seja concluída, ao invés da hierarquia

9. Equipes são nossos alicerces

10. O trabalho é organizado de modo que cada pessoa veja a relação entre sua função e as metas da organização 
11. A autoridade é delegada e assim as pessoas podem atuar com autonomia

12. A capacidade das pessoas está em constante aperfeiçoamento

13. Há investimento continuo nas habilidades dos empregados

14. As capacidades das pessoas são vistas como importante fonte de vantagem competitiva

15. Problemas costumam surgir porque não temos as habilidades necessárias para fazer o trabalho

16. Os líderes e gestores "praticam o que pregam"

17. Há um estilo de gestão próprio e práticas gerenciais nítidas

18. Existe um conjunto claro e consistente de valores que rege a forma como fazemos os negócios

19. Quando as pessoas ignoram os valores fundamentais, elas são responsabilizadas

20. Há um código de ética que norteia nosso comportamento e nos diz o que é certo e errado

21. Quando ocorrem divergências, trabalhamos intensamente para chegar a soluções ganha-ganha

22. Existe uma cultura claramente definida

23. É fácil chegar a um consenso, mesmo em questões difíceis

24. Muitas vezes, temos dificuldade de chegar a um acordo sobre questões fundamentais

25. Existe um acordo claro sobre a maneira correta e errada de fazer as coisas

26. Nossa abordagem para fazer negócios é muito consistente e previsível

27. Pessoas de áreas diferentes da organização compartilham uma perspectiva em comum

28. E fácil coordenar os projetos pelas diferentes áreas da organização

29. Trabalhar com alguém de outra área da organização é como trabalhar com alguém de uma organização diferente

30. Há um bom alinhamento das metas entre os diferentes níveis

31. A maneira como as coisas são feitas é muito flexível e fácil de mudar

32. Respondemos bem aos concorrentes e a outras mudanças do ambiente de negócios

33. Adotamos continuamente novas e melhores formas de fazer o trabalho

34. Esforços para criar mudança normalmente encontram resistência 
35. Diferentes áreas da organização frequentemente cooperam para criar mudança

36. Comentários e sugestões de clientes frequentemente resultam em mudanças

37. O "input" do cliente influencia diretamente nossas decisões

38. Todos os membros têm um entendimento profundo dos desejos e necessidades do cliente

39. Os interesses do cliente muitas vezes são ignorados em nossas decisões

40. Incentivamos o contato direto de nossos funcionários com os clientes

41. Nós pensamos que o erro é uma oportunidade para aprendizagem e melhoria

42. A inovação e a tomada de risco são estimuladas e recompensadas

43. Muita coisa é negligenciada ou esquecida

44. A aprendizagem é um objetivo importante em nosso dia a dia de trabalho

45. Garantimos que todos sejam informados sobre o que está acontecendo

46. Há um proposito e uma direção de longo prazo

47. Nossa estratégia leva outras organizações a mudar a maneira como competem na indústria

48. Há uma clara missão que dá sentido e direção ao nosso trabalho

49. Há uma estratégia clara para o futuro

50. Nossa orientação estratégica não é clara para mim

51. Existe um consenso generalizado sobre as metas

52. Os líderes definem metas que são ambiciosas, mas realistas

53. A liderança é franca em relação aos objetivos que estão tentando alcançar

54. Estamos continuamente monitorando nosso progresso em relação aos nossos objetivos declarados

55. As pessoas entendem o que precisa ser feito para que possamos ter sucesso no longo prazo

56. Temos uma visão compartilhada de como a organização será no futuro

57. Os líderes têm uma visão de longo prazo

58. Pensar no curto prazo muitas vezes compromete nossa visão de longo prazo

59. Nossa visão gera entusiasmo e motivação para nossos colaboradores

60. Somos capazes de atender a demandas de curto prazo sem comprometer a visão de longo prazo 


\section{Dados demográficos:}

Nível hierárquico (VP/Diretor, Superintendente/Gerente)

Tempo de casa (em anos completos)

Idade (em anos completos)

Gênero (masculino, feminino) 